\title{
CARACTERÍSTICAS GEOQUÍMICAS E DE POSICIONAMENTO TECTÔNICO DO MAGMATISMO NEOPROTEROZÓICO AFLORANTE NO PLATÔ DO TAQUAREMBÓ - RS
}

\author{
WILSON WILDNER ${ }^{1} \&$ LAURO VALENTIM STOLL NARDI ${ }^{2}$
}

\begin{abstract}
GEOCHEMICAL CHARACTERISTICS AND TECTONIC EMPLACEMENT OF THE NEOPROTEROZOIC MAGMATISM OF THE TAQUAREMBÓ PLATEAU, RS, bRAZIL The Neoproterozoic-Cambrian Taquarembó Plutonovolcanic Association, exposed in the Taquarembó Plateau, southern Brazil, is composed of volcanoclastic deposits, lavas and shallow intrusive rocks of silica-saturated alkaline affinity. Metaluminous basalts, basaltic andesites, dacites to trachytes, monzodiorites and rhyolites are associated with peralkaline syenites and rhyolites of comenditic affinity. Basic rocks were discriminated as low and high Ti-P, the former probably related with the metaluminous more evolved liquids and the second one with the peralkaline intermediate and acid rocks. REE, HFS and particularly $\mathrm{Zr}-\mathrm{P}$, discriminate the metaluminous and peralkaline rocks, increasing in the second group. Isotope and trace element based geochemical interpretation, suggests that both basic magmas are probably derived from the same EM1 mantle sources, and represent different melt fractions. The comenditic character, $\mathrm{Nb}$ Ta negative anomalies in MORB normalised spidergrams, low $\mathrm{Zr} / \mathrm{Nb}$ ratios, and LREE enriched patterns are suggestive of mantle sources modified by crustal subduction. Crustal influence was mostly inherited from a previous subduction and the consequent mantle metasomatism. The differentiation of parental magmas was dominantly through mineral crysytallization, involving mainly pyroxene and feldspar, with minor amounts of apatite, zircon and ilmenite. This magmatism was generated during the postcollisional period of Brasiliano Cycle, overlying the foreland of a continental margin arc.
\end{abstract}

Keywords: Camaquã basin, alkaline bimodal magmatism, withinplate magmatism.

\begin{abstract}
RESUMO A Associação Vulcano-Plutônica de idade Neoproterozóica-Cambriana aflorante no Platô do Taquarembó, esta composta por rochas vulcânicas e intrusivas rasas de afinidade alcalina saturada em sílica, onde predominam depósitos vulcanoclásticos e de fluxos de lavas, intrudidos por necks sieníticos e monzodioríticos. Baseados em ETR, elementos litófilos de alto potencial iônico (HFS) e particularmente os teores em Ti, $\mathrm{P}$ e Zr, a porção básica desta asociação foi subdividida em rochas alto e baixo Ti-P, sendo que os alto teores estão relacionados a líquidos metalıminosos mais diferenciados, enquanto que os baixo teores associam-se a rochas intermediárias e ácidas peralcalinas. Interpretações baseadas na geoquímica dos elementos traços e isótopos sugerem que tanto as rochas metaluminosas quanto peralcalinas foram derivadas a partir de uma mesma fonte, relacionada a um manto tipo EM1, e que representam diferentes graus de fusão parcial desta fonte. O caráter comendítico, as anomalias negativas de $\mathrm{Nb}$ e Ta, as baixas razões $\mathrm{Zr} / \mathrm{Nb}$ e os padrões enriquecidos em ETRL são indicativos de uma fonte modificada por metasomatismo, causado por subducção crustal. A diferenciação dos magmas parentais foi controlada dominantemente pelo fracionamento de feldspatos e piroxênios e quantidades menores de apatita, zircão e ilmenita. Este magmatismo foi gerado durante o período pós-colisional do Ciclo Brasiliano, sobre o antepaís de um arco magmático continental.
\end{abstract}

Palavras-chave: Bacia do Camaquã, magmatismo alcalino bimodal, magmatismo intraplaca.

INTRODUÇÃO O final do ciclo orogênico Brasiliano/PanAfricano no Sul do Brasil está marcado pelo desenvolvimento de espessos depósitos sedimentares, associados a expressivos volumes de rochas vulcânicas, confinados espacialmente a bacias tardi a pós-tectônicas denominadas Camaquã e Platô do Taquarembó no Rio Grande do Sul (Fig. 1) e Bacia do Itajaí em Santa Catarina. No contexto geotectônico Fragoso Cesar et al. (1992) posiciona estas bacias nas fases finais de arrefecimento da Orogenia Brasiliana, a qual teria evoluído de condições transpressivas para distensivas com a consequiente geração de antefossas e/ou bacias intermontanas assimétricas do tipo strike-slip (Almeida et al. 1981), encerrando com ambiente transtensivo associado ao relaxamento termal desta orogenia (Brito Neves \& Cordani 1991). O estudo petrológico e geoquímico das sequiências vulcânicas que preenchem estas bacias é especialmente importante para o entendimento da evolução geoló-gica desse ambiente pós-orogênico, pois elas represen- tam uma das melhores exposições de sequiências vulcanosedimentares relacionadas a bacias marginais neoproterozóicas preservadas no Brasil, proporcionando o estudo das relações estratigráficas e dos processos magmáticos que encerraram este importante evento geotectônico.

POSICIONAMENTO GEOLÓGICO REGIONAL O vulcanismo Neoproterozóico presente nas bacias intermontanas do Escudo Sul-Rio-Grandense tem sido objeto de estudos por parte de vários pesquisadores. Reconhecido desde os trabalhos pioneiros de Almeida (1949), sua conceituação, delimitação e caracterização litológica, recebeu importantes contribuições com os trabalhos de Mau (1959), Ribeiro et al. (1966), Santos et al. (1978) e Jost (1984). Estudos litoquímicos recentes e novas interpretações genéticas tem sido apresentadas por Wildner $e t$ al. (1994), Lima \& Nardi (1998), Sommer et al. (1993), Gastal (1997), Almeida et al. (1998) e Wildner \& Lima (1998).

1 CPRM - Serviço Geológico do Brasil e UFRGS - Instituto de Geociências; Rua Banco da Província, 105, CEP: 90840-030, Porto Alegre-RS, Brasil; e-mailwwildner@portoweb.com.br

2 UFRGS - Instituto de Geociências - Centro de Estudos em Petrologia e Geoquímica (CPGq); Av. Bento Gonçalves 9500), Agronomia, CEP; 91540 000 Porto Alegrc-RS, Brasil; c-mail Inardi@if.ufrgs.br: 


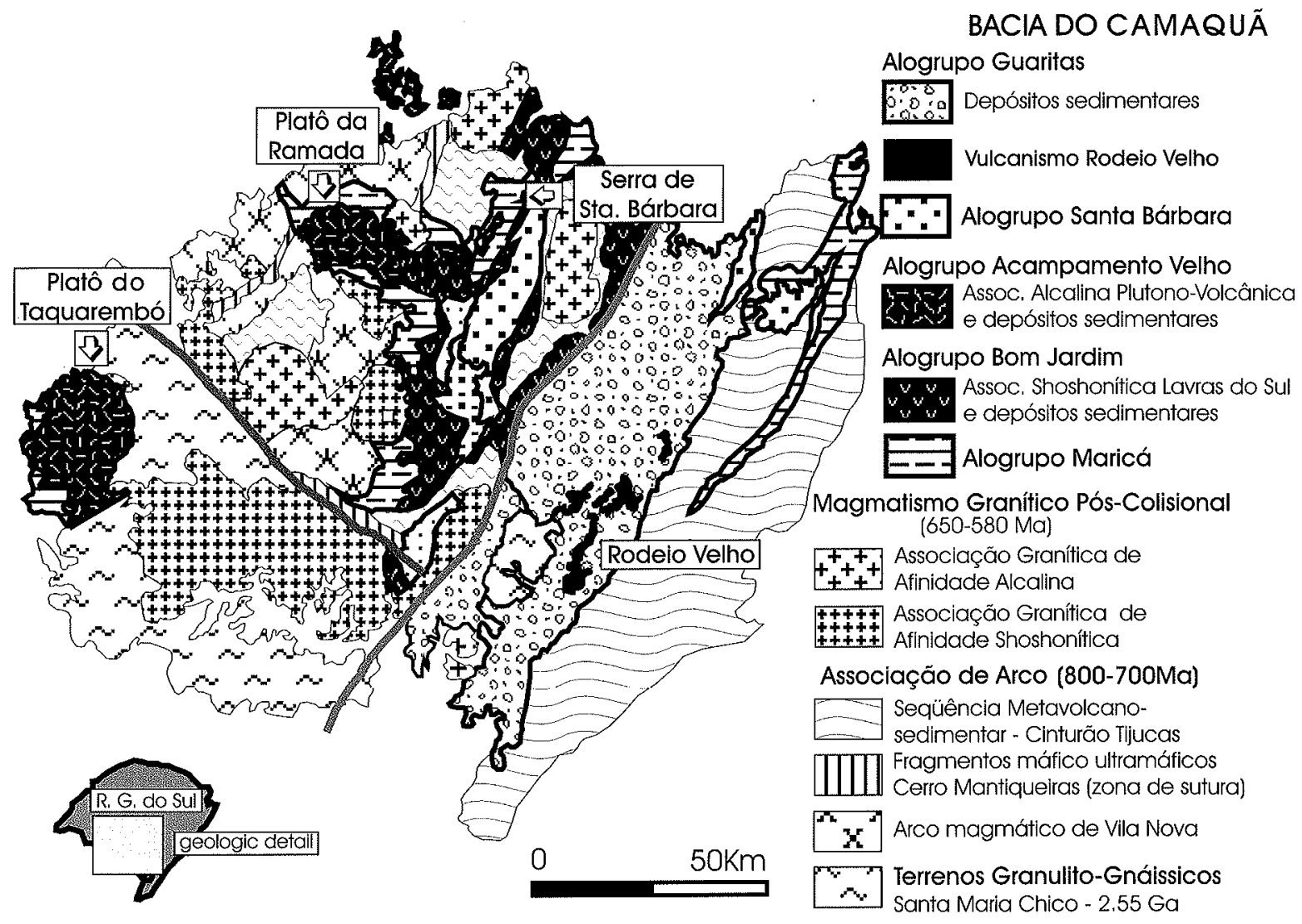

Figura I- Mapa de localização geográfica e geologia simplificada da Bacia do Camaquã (modificado de Paim et al. 1999).

O preenchimento da bacia do Camaquã (Fig. 2) inicia-se pela Formação Maricá, sensu Ribeiro et al. (1966), ou Aloformação Maricá de Paim et al. (1995), constituída por rochas sedimentares onde predominam arenitos conglomeráticos, arenitos médios a finos e pelitos com estruturas características de depósitos relacionados a ambientes continental, litorâneo e de plataforma.

O Membro Hilário do Grupo Bom Jardim de Ribeiro et al. (1966), ou Alogrupo Bom Jardim de Paim et al. (1995), está representado por lavas de traquibasaltos e traquiandesitos agrupadas na Associação Shoshonítica de Lavras do Sul de Nardi \& Lima (1985). As rochas efusivas básicas posicionam-se nas partes inferiores da sequiência, passando a composições intermediárias nas porções medianas, intercaladas com depósitos piroclásticos de queda e de fluxo. Intrusivas shoshoníticas geneticamente relacionadas a este evento estão representadas por um domo de lamprófiro espessartítico, necks monzoníticos a quartzo monzoníticos, diques de andesitos, além de plutons graníticos como o núcleo do Complexo Granítico Lavras, o Maciço Granítico Santo Antônio e o Complexo Granítico Santa Rita. O posicionamento epizonal desses granitóides marca o local de antigas câmaras magmáticas relacionadas a este evento plutono-vulcânico. Dados isotópicos U-Pb em zircão, apresentados por Remus et al. (1998) indicam idades de $592 \pm 5 \mathrm{Ma}$, com $\varepsilon N d=$ -1, para os granitóides shoshoníticos do núcleo do Complexo Granítico Lavras.

O vulcanismo riolítico a traquítico de idade Cambriana, referido no Rio Grande do Sul como Formação Acampamento Velho, sensu Horbach et al. (1986), ou Alogrupo Cerro do Bugio com a Aloformação Acampamento Velho de Paim et cl. (1999) é representado por um espesso conjunto de rochas essencialmente ígneas que repousa discordantemente sobre as Aloformações Maricá e Hilário, sendo recoberto discordantemente por rochas sedimentares Cambro-Ordovicianas da Aloformação Santa Fé. Dados isotópicos $\mathrm{Rb}-\mathrm{Sr}$ apresentados por Gastal \& Nardi (1998) forneceram idades de 566 $444 \mathrm{Ma}$ para os necks monzodioríticos a sieníticos que perfuram o Platô do Taquarembó e que foram denominados como Complexo Anelar Leões. Dados U-Pb obtidos por Remus et al. (1998) para o pertita granito aflorante na borda do Complexo Granítico Lavras, considerado como uma intrusão epizonal correlata ao vulcanismo Acampamento Velho, apresentaram uma idade de $580 \pm 7 \mathrm{Ma}$ com eNd $=+1.0$, enquanto que lavas riolíticas do Passo do Pessegueiro, apresentaram idades de $573 \pm 2 \mathrm{Ma}$ com razão inicial ${ }^{87} \mathrm{Sr} /{ }^{86} \mathrm{Sr}$ de 0,704 (Chemale et al. 1999).

A sedimentação na bacia do Camaquã encerra-se com espessos depósitos eólicos relacionados ao Alogrupo Guaritas (Paim et al. 1999), onde intercalam-se traps vulcânicos com características de rochas básicas a intermediárias, denominadas por $\mathrm{Ri}$ beiro et al.(1966) como Membro Rodeio Velho ou Aloformação Rodeio Velho, (Paim et al. 1999). Dados U-Pb apresentados por Hartmann et al. (1998) apontam uma idade de 470Ma para os derrames basálticos relacionados ao Membro Rodeio Velho aflorantes próximo ao Passo dos Enforcados, posicionando este vulcanismo no Vendiano e correlacionando-o com a Formação Três Lagoas (Lopes et al. 1999). 


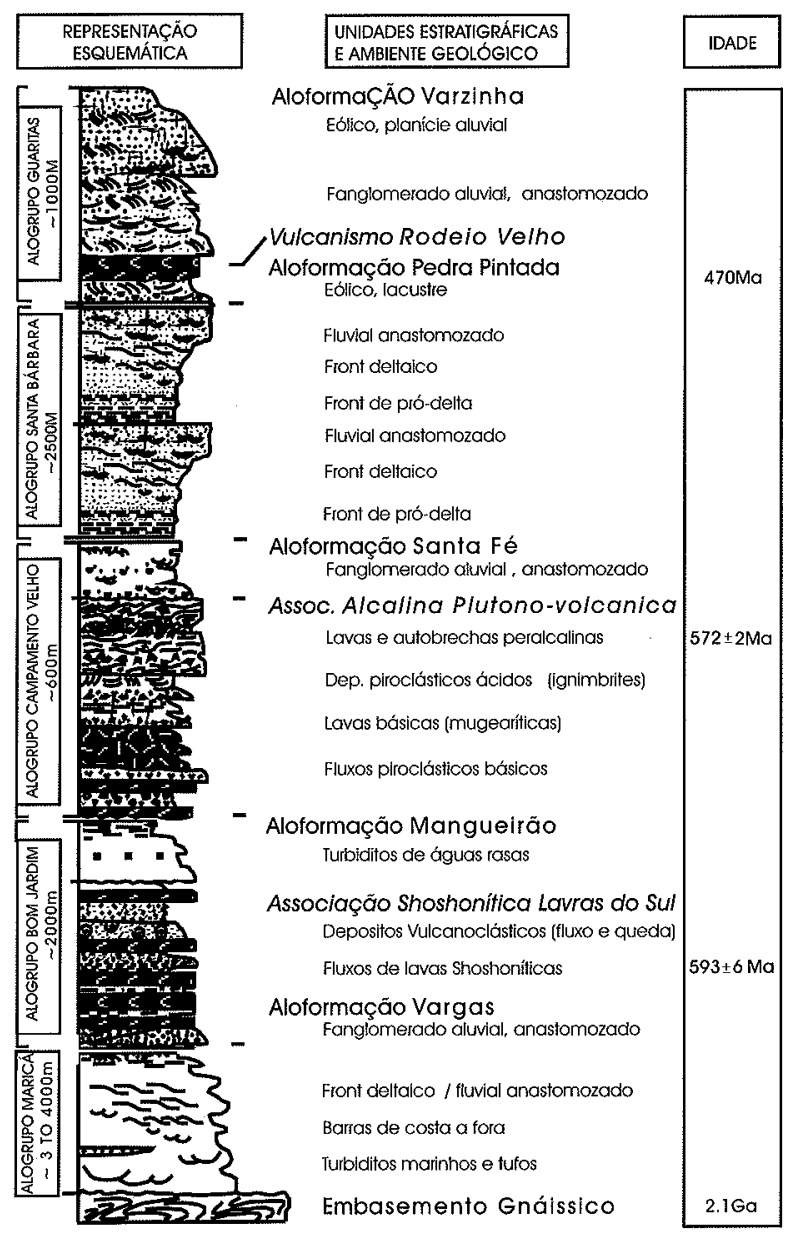

Figura 2 - Seção esquemática vertical da Bacia do Camaquã.

Afinidade geoquímica do magmatismo A caracterização geoquímica das rochas vulcano-plutônicas aflorantes no Platô do Taquarembó baseia-se nos resultados analíticos de 63 amostras de rochas, tendo sido selecionadas 19 amostras de lavas básicas, 28 de lavas ácidas e 16 amostras de intrusivas epizonais, descartando-se as amostras relacionadas a depósitos vulcanoclásticos. Os dados litoquímicos foram obtidos nos laboratórios da Activation Laboratories LTD, Ontario - Canada, onde foram analisados elementos maiores e menores por FusãoICP (Inductive Coupled Plasma), 29 elementos traço e 14 terras raras, analizados por ICP-MS (Inductive Coupled PlasmaMass Spectrometry), (Tabela 1).

Para visualizar o comportamento geoquímico do pacote aflorante, os elementos maiores foram plotados em diagramas do tipo Harker, utilizando-se como parâmetro de comparação os teores em sílica, que variam entre 45 e $76 \%$, delineando um gap composicional nas lavas entre 56 e $64 \%$ em $\mathrm{SiO}_{2}$ (Fig. 3). Destaca-se a linearidade em todo o conjunto para os elementos $\mathrm{CaO}$, $\mathrm{FeO}^{*}$ e $\mathrm{TiO}_{2}$ e o espalhamento para elementos como $\mathrm{Al}_{2} \mathrm{O}_{3}$, $\mathrm{K}_{2} \mathrm{O}, \mathrm{Na}_{2} \mathrm{O}^{2} \mathrm{P}_{2} \mathrm{O}_{5}$.

Embora se admita a possibilidade da perda em álcalis durante o resfriamento ou alterações pós-magmáticas dos diferentes litótipos vulcano-plutônicos que compõem o Platô do Taqua- rembó, utilizando-se o diagrama TAS de classificação (Le Bas et. al. 1986) (Fig.4) constata-se o caráter alcalino saturado em sílica para a associação, onde as lavas básicas posicionam-se entre basaltos, traqui basalto-andesitos e basalto-andesitos, sobre a linha divisória das séries sub-alcalinas e alcalinas de Kuno (1968). As rochas vulcânicas ácidas são classificadas como traquitos e riolitos, enquanto que as rochas intrusivas formam dois conjuntos, um no campo dos traquiandesitos e outro no limite entre os traquitos e dacitos. A projeção destas composições em diagramas de razões de elementos de baixa mobilidade, como $\mathrm{Zr} / \mathrm{TiO}_{2}$ vs $\mathrm{SiO}_{2}$ e vs $\mathrm{Ga}$ (Winchester \& Floyd 1977) confirma esta distribuição de amostras (Fig. 5), onde as lavas básicas concentram-se entre os basaltos alcalinos e traquiandesitos, enquanto que os termos intrusivos dividem-se entre os traquiandesitos, riodacitos e dacitos, acompanhados pelas lavas ácidas no campo dos riolitos peralcalinos (comenditos e panteleritos) e dos riolitos metaluminosos. Destacam-se os elevados teores em Ga e $\mathrm{Zr}$ nos termos ácidos e a distribuição das intrusivas em duas populações, uma relacionada ao campo dos comenditos e outra com os basaltos alcalinos.

Tendo-se em vista o diversificado grau de alcalinidade e a possibilidade da coexistência de composições químicas contras-tantes nas litologias que compõem o Platô, selecionou-se o $\mathrm{Zr}$ como parâmetro discriminatório entre estas composições, uma vez que seu comportamento apresenta características distintivas entre diferentes tipos de magmas, Leat et al. (1986). Utilizando este parâmetro nos diagramas $\mathrm{Na}_{2} \mathrm{O}, \mathrm{TiO}_{2}, \mathrm{Nb}$ e $\mathrm{Y} v s$ $\mathrm{Zr}$ (Fig. 6), torna-se clara a existência de duas concentrações de pontos, uma no campo do baixo $\mathrm{Zr}$ com teores variando entre 150 e $450 \mathrm{ppm}$ (contendo todas as lavas básicas, algumas das lavas ácidas e parte das rochas intrusivas) e uma segunda concentração com valores destacadamente elevados em $\mathrm{Zr}$, que variam entre 650 e $1100 \mathrm{ppm}$ (contendo parte das lavas ácidas e parte das rochas intrusivas), delineando um gap entre 500 e 650ppm. Utilizando-se da conceituação de Leat et al. (1986), onde o $\mathrm{Zr}$ pode ser usado para identificar as características peralcalinas ou subalcalinas de sequiências vulcânicas, onde especialmente os álcalis já não apresentam confiabilidade para uma caracterização litogeoquímica, e onde teoricamente os teores de $\mathrm{Zr}$ servem para delimitar séries com diferentes relações álcalis/alumina, refletindo a alta solubilidade do $\mathrm{Zr}^{+4} \mathrm{em}$ magmas com altas razões $\mathrm{Na}+\mathrm{K}$ sobre os cátions formadores de rede ( $\mathrm{Al}$ e $\mathrm{Si}$ ); Constata-se, através deste parâmetro, que as rochas aqui discutidas dividem-se em duas associações litológicas, uma com características metalu-minosas, composta dominantemente por basaltos alcalinos, quartzo monzonitos e riolitos, e outra com características peralcalinas composta por intrusões sieníticas e lavas riolíticas de características commendíticas. Considerando-se conjuntamente os diagramas de Harker, a classificação litológica e a definição com base nos teores de $\mathrm{Zr}$, sugere-se que o Platô do Taquarembó contem duas associações litológicas, uma metaluminosa com basaltos alcalinos, quartzo monzonitos e riolitos metaluminosos, denominada informalmente de Rochas Alcalinas Metaluminosas - RAM, e outra com basaltos, sienitos e riolitos comendiíticos, denominada de Rochas Peralcalinaa Comendíticaa - RPC. Ambas associações compõem uma suíte alcalina denominada de Associação Vulcano-Plutônica Taquarembó - AVPT.

ROCHAS ALCALINAS METALUMINOSA - RAM NO 
Tabela 1 - Composição quínica representativa de amostras da Associação Vulcano-Plutônica Taquarembó; elementos maiores em percentagem; elementos traço em ppm. la - lavas ácidas, lb-lavas básicas, int-intrusivas.

\begin{tabular}{|c|c|c|c|c|c|c|c|c|c|c|c|c|}
\hline Amostra & $\begin{array}{l}W W \\
22 *\end{array}$ & $\begin{array}{l}\text { W W } \\
82^{*} \\
\end{array}$ & $\begin{array}{l}\text { W W } \\
28^{\wedge} \\
\end{array}$ & $\begin{array}{l}W W \\
80^{\wedge} \\
\end{array}$ & $\begin{array}{l}\text { W W } \\
47 \# \\
\end{array}$ & $\begin{array}{l}\text { WW } \\
24 a \#\end{array}$ & $\begin{array}{l}\text { W W } \\
07+ \\
\end{array}$ & $\begin{array}{l}\text { WW } \\
85+\end{array}$ & $\begin{array}{l}\text { W W } \\
06 a^{\prime}\end{array}$ & $\begin{array}{l}\text { W W } \\
18 a^{\prime}\end{array}$ & $\begin{array}{l}\text { W W } \\
33 \mathrm{~b}^{\prime \prime}\end{array}$ & $\begin{array}{l}\text { W W } \\
63^{\prime \prime}\end{array}$ \\
\hline $\mathrm{SiO}_{2}$ & 48,83 & 53,59 & 49,07 & 56,64 & 66,28 & 60,04 & 58,71 & 59,65 & 74,47 & 70,30 & 66,25 & 72,17 \\
\hline $\mathrm{Al}_{2} \mathrm{O}_{3}$ & 14,36 & 15,66 & 13,53 & 16,66 & 13,46 & 14,83 & 13,48 & 13,77 & 11,95 & 12,65 & 14,33 & 13,89 \\
\hline $\mathrm{Fe}_{2} \mathrm{O}_{3}$ & 11,81 & 9,24 & 13,02 & 7,43 & 4,20 & 6,15 & 9,41 & 8,76 & 4,18 & 5,64 & 5,96 & 2,87 \\
\hline $\mathrm{MnO}$ & 0,16 & 0,17 & 0,21 & 0,12 & 0,08 & 0,08 & 0,26 & 0,25 & 0,02 & 0,06 & 0,25 & 0,07 \\
\hline $\mathrm{MgO}$ & 5,90 & 3,88 & 6,65 & 4,17 & 1,18 & 2,68 & 1,63 & 1,92 & 0,04 & 0,12 & 0,24 & 0.69 \\
\hline $\mathrm{CaO}$ & 8,80 & 6,59 & 10,81 & 7,08 & 2,95 & 3,69 & 3,03 & 3,02 & 0,05 & 0,09 & 1,89 & 0,41 \\
\hline $\mathrm{a}_{2} \mathrm{O}$ & 2,83 & 3,21 & 2,18 & 3,07 & 3,26 & 4,15 & 4,24 & 4,13 & 3,95 & 4,11 & 4,87 & 4,73 \\
\hline $\mathrm{K}_{2} \mathrm{O}$ & 1,50 & 2,27 & 0,49 & 2,00 & 4,11 & 3,03 & 4,36 & 4,38 & 4,21 & 3,46 & 4,98 & 4,44 \\
\hline $\mathrm{iO}_{2}$ & 2,00 & 1,96 & 1,18 & 1,07 & 0,91 & 0,90 & 1,45 & 1,29 & 0.25 & 0,34 & 0,62 & 0,46 \\
\hline $\mathrm{P}_{2} \mathrm{O}_{5}$ & 0,74 & 0,88 & 0,14 & 0,44 & 0,37 & 0,68 & 0,43 & 0,43 & 0,04 & 0,08 & 0,14 & 0,10 \\
\hline P.F. & 2,18 & 2,05 & 1,70 & 1,83 & 2,45 & 1,80 & 1,94 & 1,89 & 0,81 & 1,73 & 0,95 & 0,95 \\
\hline Total & 99,12 & 99,49 & 98,98 & 100,51 & 99,25 & 98,02 & 98,92 & 99,48 & 99,96 & 98,56 & 100,49 & 100,79 \\
\hline $\mathrm{Sc}$ & 36 & 21 & 44 & 16 & 10 & 10 & 28 & 30 & 1 & 10 & 25 & 6 \\
\hline $\mathrm{Be}$ & 1 & 2 & -1 & 2 & 2 & 2 & 3 & 4 & 3 & 3 & 2 & 2 \\
\hline V & 213 & 135 & 314 & 106 & 74 & 90 & 35 & 41 & 10 & -5 & -5 & 27 \\
\hline $\mathrm{Cr}$ & 171 & 16 & 100 & 140 & -10 & 38 & -10 & -10 & -10 & -10 & -10 & 14 \\
\hline $\mathrm{Co}$ & 38 & 22 & 51 & 24 & 6,4 & 15 & 5,4 & 5,5 & 0,9 & 1,6 & 0,8 & 5 \\
\hline $\mathrm{Ni}$ & 95 & 14 & 57 & 70 & -10 & 23 & -10 & -10 & 10 & -10 & 10 & -10 \\
\hline $\mathrm{Cu}$ & 24 & 34 & 158 & 37 & 17 & 19 & 14 & 12 & 14 & 12 & 13 & 15 \\
\hline $\mathrm{Zn}$ & 100 & 104 & 72 & 95 & 57 & 165 & 163 & 154 & 43 & 98 & 78 & 50 \\
\hline $\mathrm{G} a$ & 19 & 22 & 18 & 21 & 19 & 21 & 25 & 30 & 28 & 24 & 20 & 21 \\
\hline $\mathrm{Ge}$ & 1,6 & 2,1 & 1,8 & 1,4 & 1,3 & 1,2 & 2,3 & 2,2 & 0,9 & 2,8 & 2,2 & 0,9 \\
\hline As & -5 & -5 & -5 & -5 & -5 & -5 & -5 & -5 & -5 & -5 & -5 & -5 \\
\hline $\mathrm{Rb}$ & 24 & 31 & 8,4 & 23 & 94 & 78 & 53 & 52 & 98 & 65 & 49 & 100 \\
\hline $\mathrm{Sr}$ & 398 & 503 & 181 & 569 & 353 & 776 & 150 & 187 & 48,1 & 63,2 & 117 & 117 \\
\hline Y & 41 & 45 & 28 & 31 & 29 & 19 & 85 & 91 & 90 & 69 & 46 & 37 \\
\hline $\mathrm{Zr}$ & 266 & 397 & 98 & 337 & 293 & 288 & 883 & 1149 & 1068 & 889 & 434 & 357 \\
\hline $\mathrm{Nb}$ & 10 & 15 & 6,4 & 15 & 17 & 36 & 29 & 32 & 60 & 46 & 2.5 & 27 \\
\hline Mo & 0,5 & 1 & $-0,1$ & 1.4 & 2,4 & 1,5 & 3,3 & 1,7 & 1 & 0,2 & 0,5 & 1,2 \\
\hline $\mathrm{Ag}$ & $-0,5$ & $-0,5$ & $-0,5$ & $-0,5$ & $-0,5$ & $-0,5$ & $-0,5$ & $-0,5$ & $-0,5$ & $-0,5$ & $-0,5$ & $-0,5$ \\
\hline In & $-0,1$ & $-0,1$ & $-0,1$ & $-0,1$ & $-0,1$ & $-0,1$ & $-0,1$ & 0,1 & 0,1 & 0,1 & $-0,1$ & $-0,1$ \\
\hline S & 1,4 & 3,7 & 1,3 & 2,5 & $2, I$ & 2 & 6,4 & 4,1 & 7,1 & 4,9 & 3,2 & 3,6 \\
\hline S & 0,13 & 0,16 & $-0,0 \mathrm{I}$ & 0,08 & 0,21 & 0,07 & 0,05 & $-0,05$ & 0,12 & 0,2 & 0,1 & 0,08 \\
\hline Cs & 1,3 & 0,6 & 0,2 & 0,2 & 0,6 & 0,9 & 0,4 & 0,3 & 0,5 & 0,8 & 0,3 & 0,2 \\
\hline $\mathrm{Ba}$ & 889 & 1651 & 139 & 1408 & 2039 & 1605 & 1357 & 1364 & 109 & 677 & 323 & 1170 \\
\hline $\mathrm{L}$ & 43,2 & 78,7 & 9,8 & 64,9 & 84,9 & 92,3 & 135 & 126 & 110 & 156 & 112 & 149 \\
\hline $\mathrm{Ce}$ & 93,7 & 166 & 21,5 & 124 & 158 & 176 & 284 & 263 & 250 & 313 & 220 & 272 \\
\hline $\mathrm{Pr}$ & 11,65 & 19,74 & 2,793 & 14,05 & 29,73 & 18,19 & 33,1 & 31,83 & 26,29 & 33,43 & 23,73 & 26,39 \\
\hline $\mathrm{Nd}$ & 48,2 & 76,6 & 13,8 & 50,9 & 54,3 & 67,8 & 126 & 123 & 99,8 & 130 & 97.2 & 91,2 \\
\hline $\mathrm{Sm}$ & 9,61 & 14 & 3,91 & 8,48 & 8,8 & 10,7 & 21,3 & 21,6 & 18,8 & 20,7 & 15,6 & 14 \\
\hline $\mathrm{Eu}$ & 2,624 & 4,142 & 1,361 & 2,124 & 2,074 & 2,123 & 3,816 & 3,877 & 0,406 & 1,264 & 3,179 & 2,079 \\
\hline $\mathrm{Gd}$ & 8,35 & 11 & 4,52 & 6,23 & 6,04 & 6,62 & 16 & 17 & 13,6 & 14 & 10,9 & 9,22 \\
\hline $\mathrm{Tb}$ & 1,23 & 1,61 & 0,86 & 0,92 & 0,91 & 0,89 & 2,39 & 2,58 & 2,64 & 2,37 & 1,69 & 1,4 \\
\hline Dy & 6,92 & 8,56 & 5,26 & 5,11 & 4,7 & 4,11 & 13,5 & 14,9 & 15,9 & 13,1 & 9,01 & 7,05 \\
\hline $\mathrm{H}$ & 1,29 & 1,68 & 1,08 & 0,96 & 0,91 & 0,73 & 2,74 & 2,98 & 3,34 & 2,54 & 1,7 & 1,33 \\
\hline $\mathrm{Er}$ & 3,71 & 4,76 & 3,15 & 2,82 & 2,7 & 2,06 & 7,93 & 8,84 & 10,4 & 7,76 & 5,01 & 3,92 \\
\hline $\mathrm{Tm}$ & 0,523 & 0,647 & 0,48 & 0,404 & 0,375 & 0,257 & 1,257 & 1,451 & 1,664 & 1,201 & 0,726 & 0,553 \\
\hline Yb & 3,15 & 4,05 & 3,01 & 2,35 & 2,44 & 1,53 & 7,85 & 8,86 & 10,5 & 7,47 & 4,56 & 3,44 \\
\hline Lu & 0,466 & 0,589 & 0,46 & 0,364 & 0,364 & 0,217 & 1,222 & 1,388 & 1,605 & 1.198 & 0,716 & 0,508 \\
\hline $\mathrm{Hf}$ & 5,6 & 9 & 2,8 & 6,6 & 6,4 & 6,8 & 21 & 29 & 29 & 24 & 10 & 9,5 \\
\hline $\mathrm{Ta}$ & 0,63 & 1,03 & 0,4 & 0,84 & 1,43 & 2,05 & 1,71 & 1,86 & 2,93 & 2,08 & 1,19 & 1,64 \\
\hline W & 1,6 & 2,4 & 0,7 & 2,1 & 0,7 & 1,4 & 1,9 & 0,7 & 3,5 & 1,9 & 3,5 & 2,8 \\
\hline TI & 0,11 & 0,2 & 0,07 & 0,12 & 0,45 & 0,48 & 0,18 & 0,18 & 0,32 & 0.2 & 0,21 & 0,39 \\
\hline $\mathrm{Pb}$ & 8 & 21 & -5 & 18 & 34 & 110 & 36 & 28 & 18 & 26 & 23 & 72 \\
\hline $\mathrm{B} \mathrm{i}$ & 0,07 & $-0,05$ & $-0,05$ & $-0,05$ & $-0,05$ & $-0,05$ & $-0,05$ & $-0,05$ & 0,08 & 0,06 & $-0,05$ & 0,06 \\
\hline Th & 1,87 & 5,65 & 2 & 4,91 & 16,8 & 12,2 & 7,68 & 9,05 & 15,3 & 11,6 & 5,13 & 16,6 \\
\hline $\mathrm{U}$ & $0,27 \mid$ & 0,651 & 0,41 & 0,6 & 2,12 & $2,37 \mid$ & 1,37 & 1,73 & 2,27 & 1,911 & 0,51 & 2,81 \\
\hline
\end{tabular}



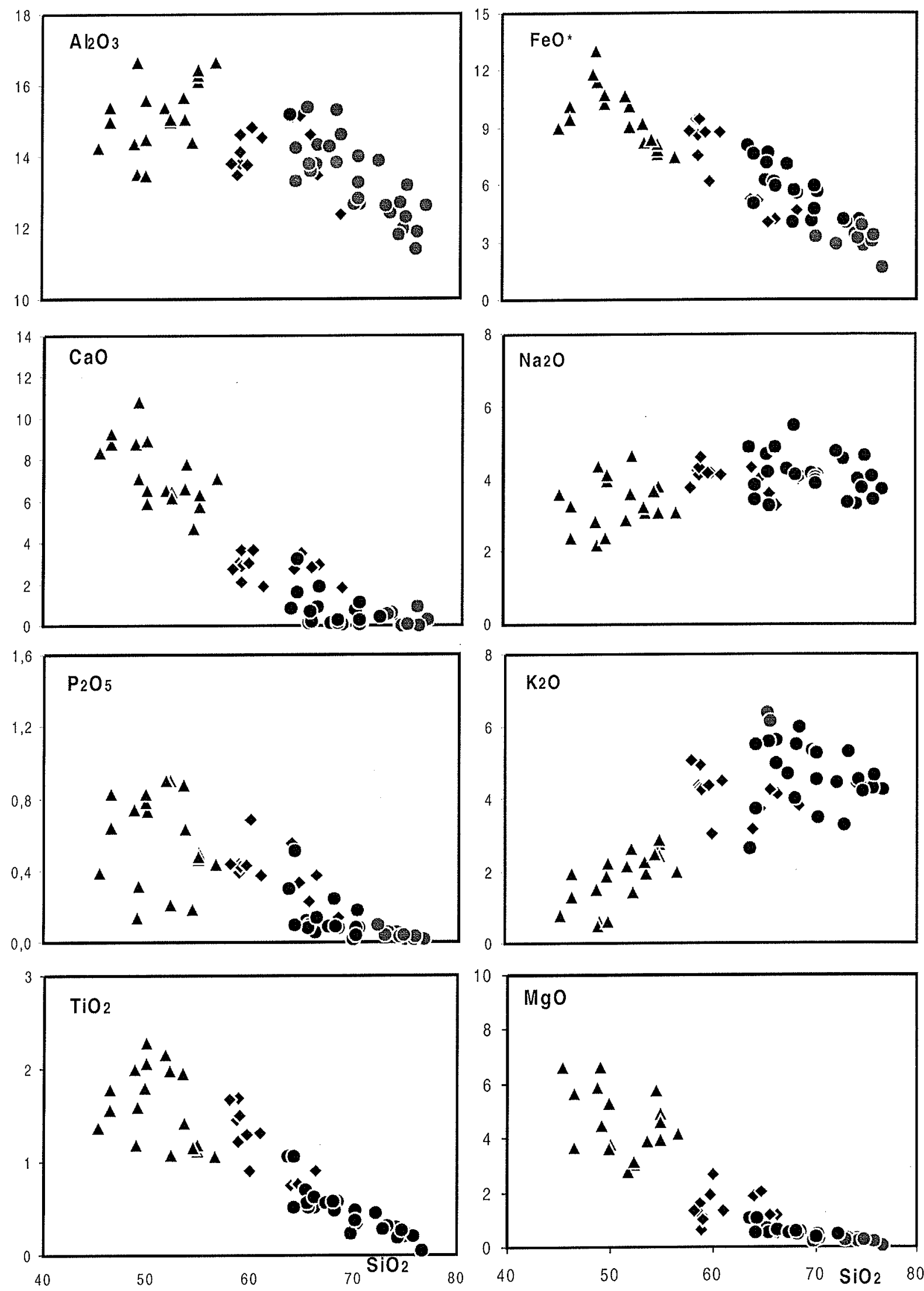

Figura 3 - Diagramas de Harker expressando as principais variações entre elementos maiores e sílica para o conjunto litológico da AVPT; círculos - lavas ácidas; triângulos - lavas básicas; losângulos - intrusivas. 


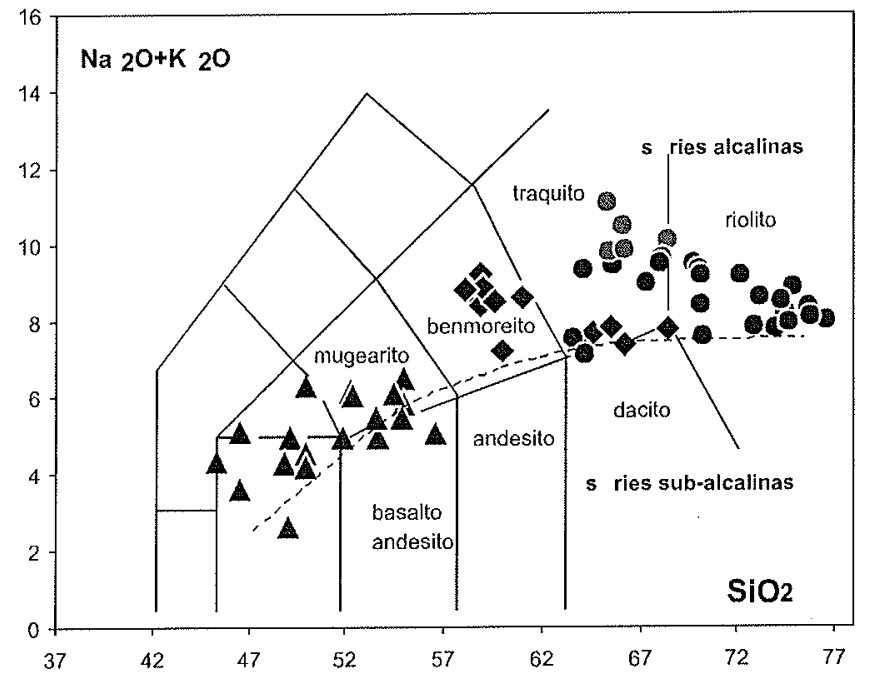

Figura 4 - Diagrama álcalis total vs sílica (TAS-Le Bas et al. 1986) contendo as amostras da Associação VulcanoPlutônica Taquarembó e o limite entre as séries sub-alcalinas $e$ alcalinas de Kuno (1968); Simbolos como na Fig. 3.

detalhamento das rochas metaluminosas da AVPT utilizou-se, como parâmetros de comparação, elementos maiores e traço presentes em basaltos alcalinos relacionados a ambientes internos a placas continentais e que, segundo MacDonald \& Bailey (1973), Wood, Tarney \& Weaver (1981) e Reid (1995), apresentam-se enriquecidos em $\mathrm{Sr}$ e $\mathrm{P}_{2} \mathrm{O}_{5}$ seguidos de $\mathrm{Rb}, \mathrm{Zr}$, Hf, Sm, $\mathrm{Ti}, \mathrm{Y}$ e Yb em relação a basaltos calcialcalinos alto-K relacionados a ambientes relacionados a subducção.

As RAM apresentam particularidades que são características de associações alcalinas, em relação a distribuição dos elementos menores e traços, onde basaltos alcalinos e termos traquíticos são levemente mais ricos em $\mathrm{TiO}_{2}, \mathrm{P}_{2} \mathrm{O}_{5}$ e $\mathrm{Zr}$ que as associações de arco vulcânico. Os basaltos alcalinos metaluminosos apresentam dois conjuntos com teores levemente distintos para $\mathrm{TiO}_{2}$ e $\mathrm{P}_{2} \mathrm{O}_{5}$, sendo um alto $\mathrm{TiO}_{2}(1.56-2.28)$ e $\mathrm{P}_{2} \mathrm{O}_{5}$ $(0.63-0.90)$ e outro baixo $\mathrm{TiO}_{2}(1.07-1.56)$ e $\mathrm{P}_{2} \mathrm{O}_{5}(0.21-0.50)$, os quais mantem uma correlação positiva do $\mathrm{P}_{2} \mathrm{O}_{5}$ com o Ce, $\mathrm{Ba}$, $\mathrm{Zr}$, Y, Rb e Sr e compõem dois grupos de amostras (Fig.7). A presença de basaltos alto e baixo Ti tem sido descrita como coexistentes em uma série de seqüências vulcânicas, normalmente relacionadas a zonas de subducção, como as descritas por Civetta et al. (1998) para a região da Pantelleria, ou Walker et al. (1993) para a margem continental ativa da América Central. Nestas regiões as diferenças entre os basaltos alto e baixo $\mathrm{TiO}_{2}$ estão relacionadas a fonte, sendo ambos os sub-tipos gerados ao longo da região sob influência da cunha de manto, onde os magmas primários baixo $\mathrm{TiO}_{2}$ podem provir de regiões onde a assinatura da faixa de subducção seja acentuada, enquanto os alto $\mathrm{TiO}_{2}$ são gerados em uma porção da cunha onde a influência da zona de subducção é mais tênue.

Para os basaltos pertencentes ao grupo das RAM rejeitamse as possibilidades das diferenças em Ti-P estarem relacionadas a diferentes níveis de contaminação por assimilação crustal, pois a assimilação desta reduziria os teores em $\mathrm{MgO}$, concomitante com o decréscimo nos teores em $\mathrm{P}_{2} \mathrm{O}_{5}$ e a variações e interferências nos padrões de distribuição de $\mathrm{Sr}, \mathrm{Nd}, \mathrm{Pb}, \mathrm{e}$ das razões como $\mathrm{Nb} / \mathrm{Ta}$ e $\mathrm{Er} / \mathrm{Y}$, o que não foi identificado na região
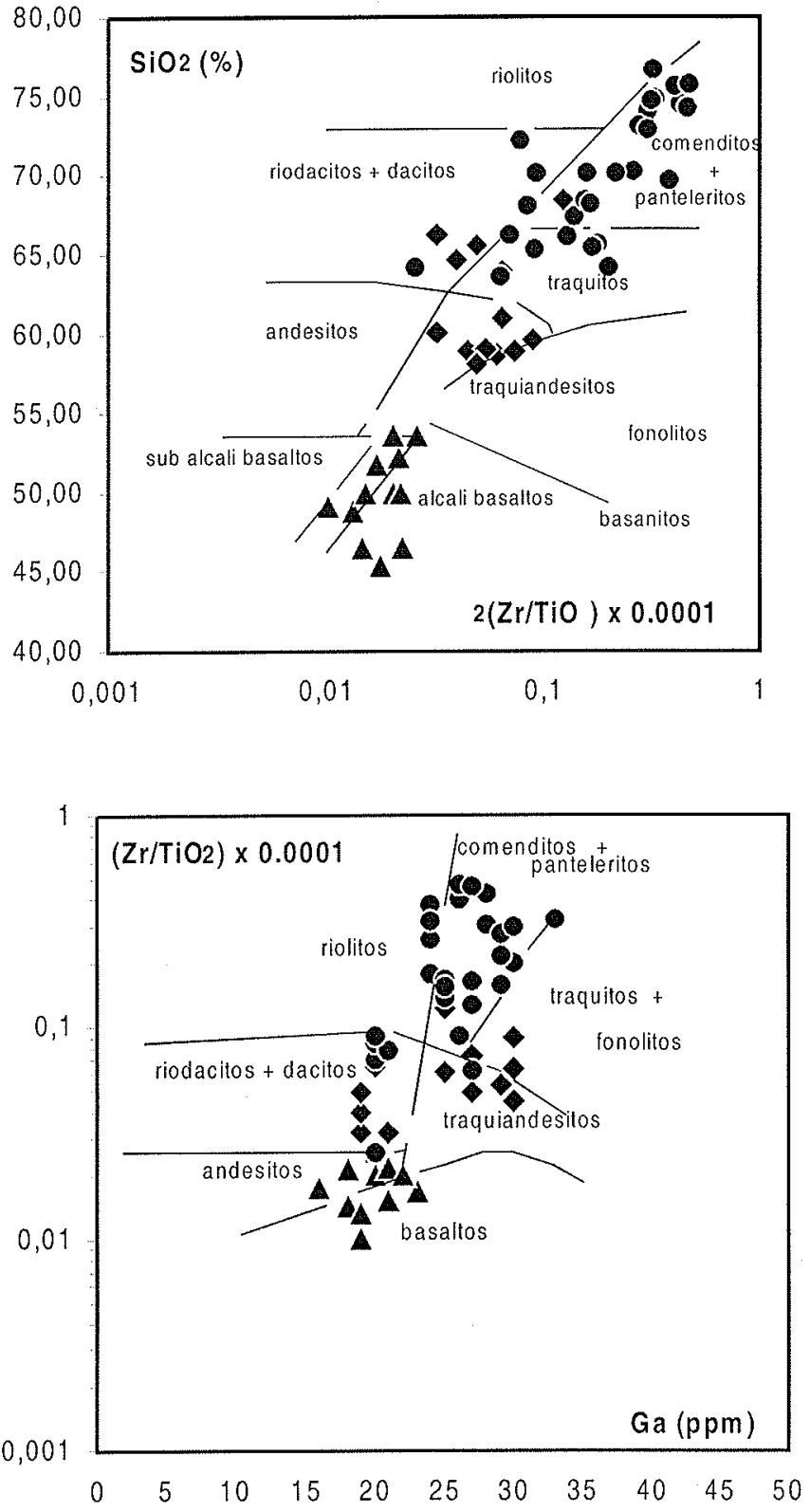

Figura 5 - Diagramas ( $\mathrm{Zr} / \mathrm{TiO} 2$ ) vs $\mathrm{SiO}_{2}$ e $\mathrm{Ga}$ com a classificação geral da Associação Vulcano-Plutônica Taquarembó (Winchester \& Floyd 1977); Símbolos como na Fig. 3.

do Platô. Para o conjunto de amostras estudado verifica-se a manutenção da linearidade entre essas razões (Fig. 8), apontando para uma evolução magmática sem interferências substanciais de contaminações externas, onde os termos alto e baixo Ti-P são provavelmente provenientes de uma mesma fonte, mas produzidos por diferentes proporções de fusão. Tomando-se como base de comparação os teores de saturação em apatita destes magmas, o qual é linearmente dependente da temperatura e dos teores em $\mathrm{SiO}_{2}$, (Reid 1995) e observando-se a distribuição das amostras de basaltos alcalinos neste espaço (Fig.9), constatase que as rochas com teores mais elevados de $\mathrm{P}_{2} \mathrm{O}_{5}$ posicionam-se entre as isotermas de $900 \mathrm{e} 1000^{\circ} \mathrm{C}$ e as mais pobres sobre a de $800^{\circ} \mathrm{C}$. Esta distribuição reforça a possibilidade da coe- 


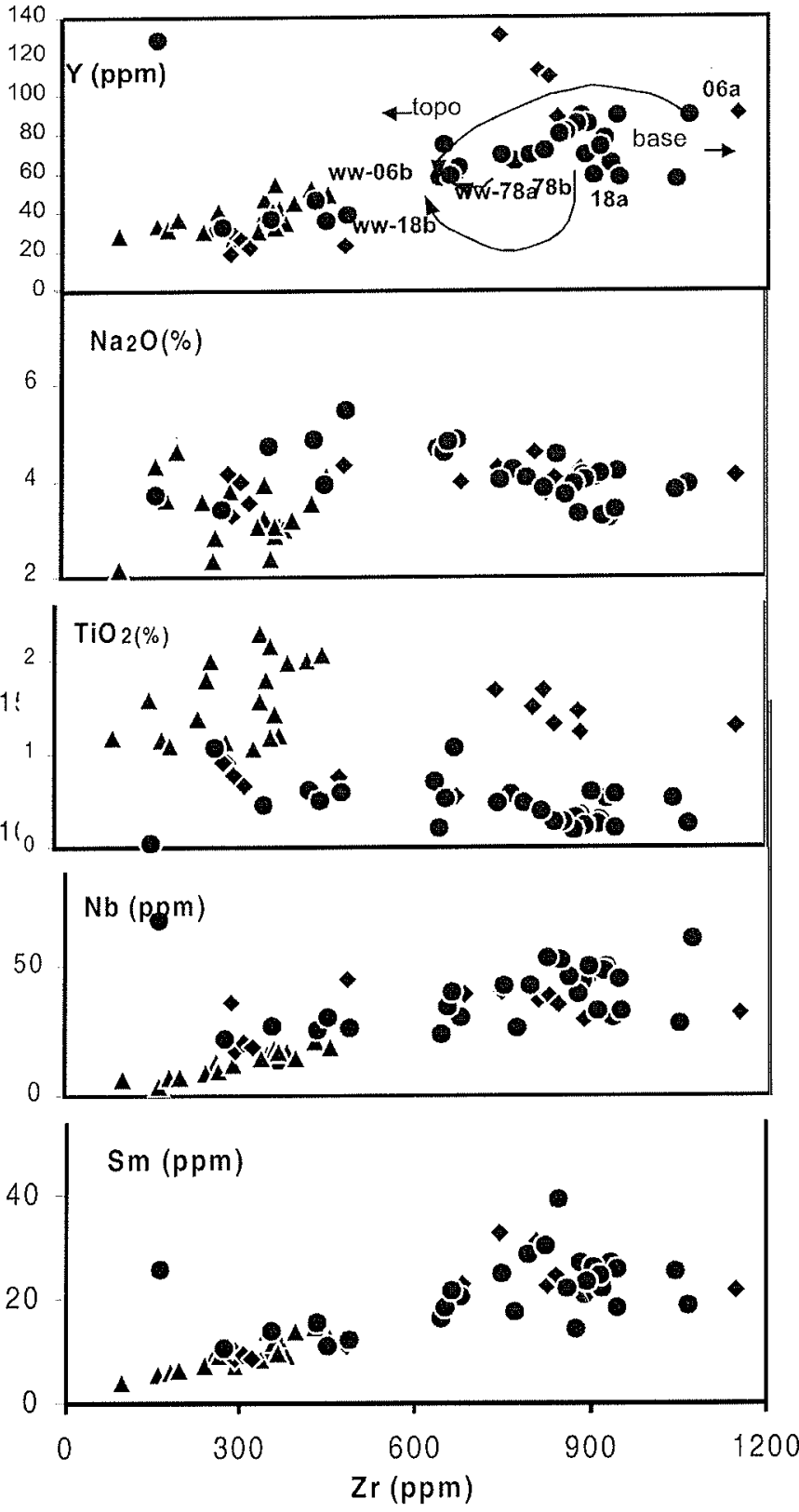

Figura 6 - Diagramas utilizando o $\mathrm{Zr}$ como elemento de comparação entre as diferentes litologias que compõe a AVPT; adetalhe comparado a distribuição de $\mathrm{Zr}$ em relação ao $Y$ mostrando as variaçôes entre amostras coletadas no topo e base de um mesmo derrame; em b-distribuição das lavas ácidas e intrusivas nos campos alto e baixo $\mathrm{Zr}$ e a presença do gap composicional; Símbolos como na Fig. 3.

xistência de dois líquidos levemente distintos, onde os com altos teores de Ti-P estariam relacionados a fusão de zonas com baixo conteúdo de voláteis, o que exigiriam maiores temperaturas de fusão. A saturação e consequiente fracionamento precoce da apatita tornaria o $\mathrm{P}_{2} \mathrm{O}_{5}$ fortemente compatível durante a diferenciação magmática, restando termos riolíticos finais, mesmo do magmatismo rico em Ti e $\mathrm{P}$, com teores compativeis aos encontrado nos termos alcalino.
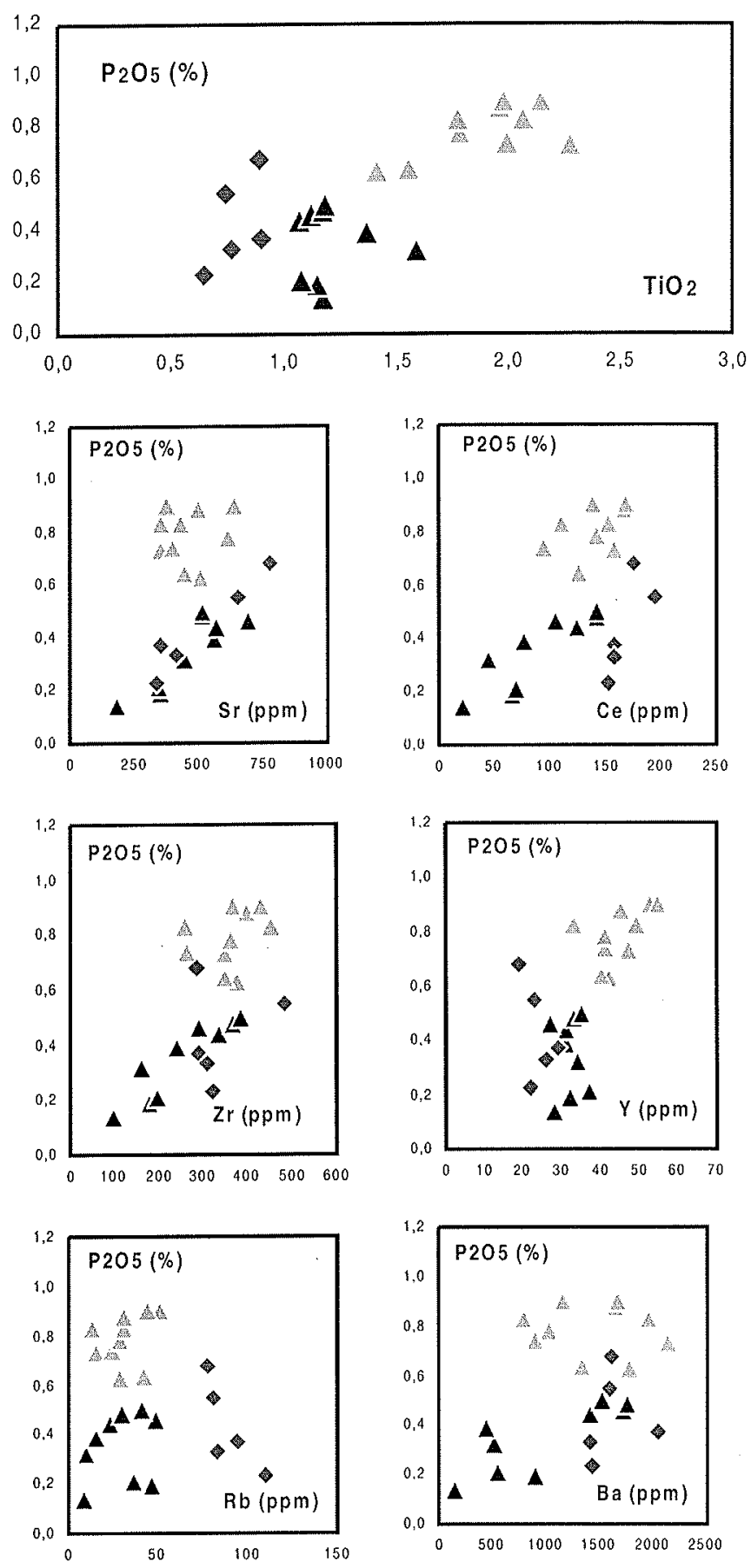

Figura 7 - Diagramas discriminantes entre basaltos alto e baixo $\mathrm{TiO}_{2}, \mathrm{P}_{2} \mathrm{O}_{5}$; Simbologia: triângulos escuros-alto Ti-P, triângulos claros- baixo Ti-P, losângulos-intrusivas.

A assimilação de crosta normalmente gera um decréscimo na razão $U / T h$, pois estes elementos apresentam um baixo coeficiente de partição com as principais fases minerais, necessitando de um alto grau de diferenciação em sistemas fechados, ou da cristalização de fases minerais acessórias específicas que concentrem preferencialmente um destes elementos, relacionados a um largo tempo de residência crustal, para que hajam modificações nesta razão. Observando-se o diagrama $U$ vs Th proposto 

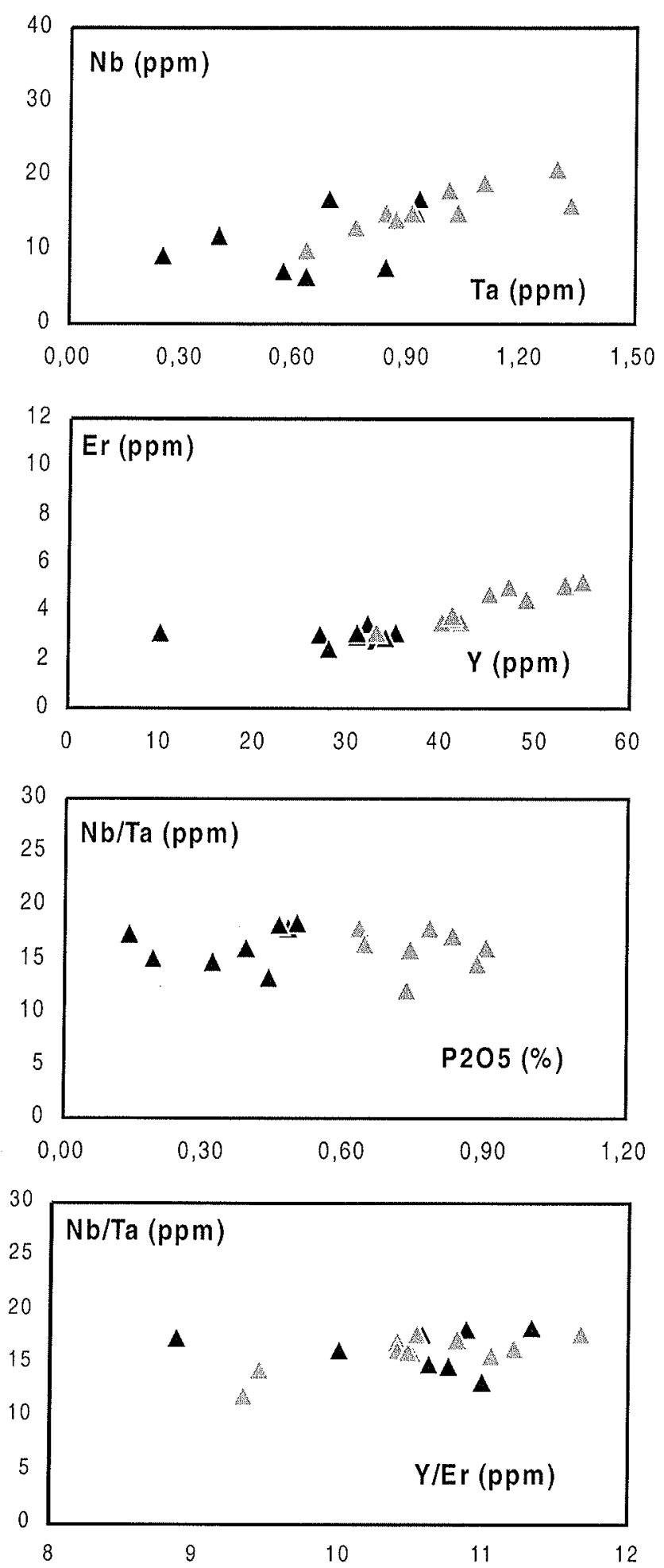

Figura 8 - Razões entre os elementos $\mathrm{Nb}, \mathrm{Ta}, \mathrm{Er} ; \mathrm{Y}$ e P2OS, onde verifica-se a manutenção da linearidade en todo o conjunto de amostras; Símbolos como na Fig. 7.

por Black et al. (1997), (Fig. 10) verifica-se que, apesar das baixas concentrações em $U(<5.12 \mathrm{ppm})$ e Th $(<34.6 \mathrm{ppm})$, todas as amostras apresentam uma relação de estreita linearidade, e que a razão $\mathrm{Th} / \mathrm{U}$ mantém uma relação de paralelismo, significando

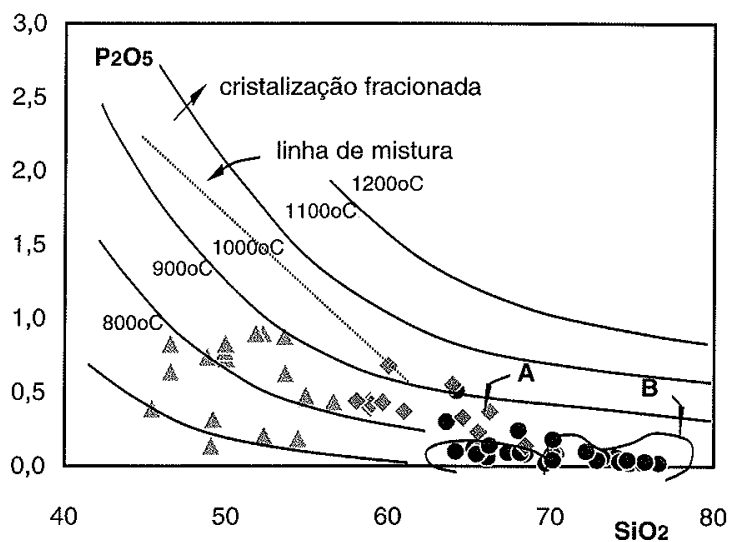

Figura 9 - Diagrama mostrando a distribuição dos basaltos com diferentes teores em $\mathrm{P}_{2} \mathrm{O}_{5}$ em relação as isotermas entre 800 e $1200^{\circ} \mathrm{C}$, e a posição dos termos ácidos em relação ao campo dos riolitos de Snake River Plain e o Batólito de Idaho, Reid (1995); símbolos como na Fig. 7.

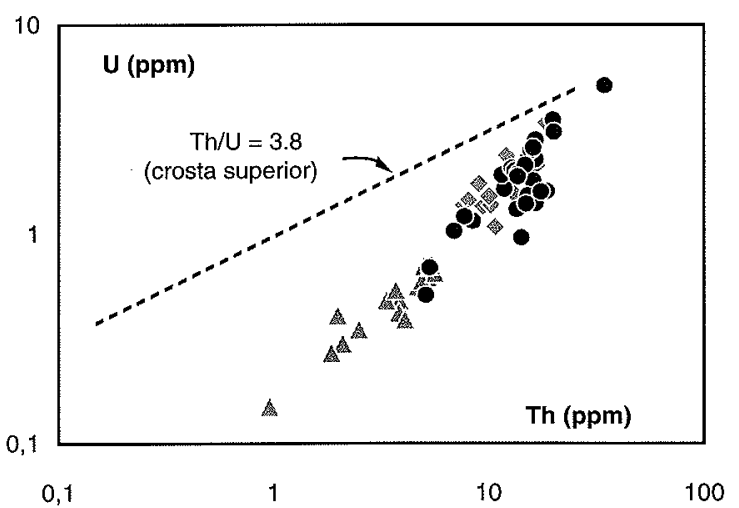

Figura 10 - Diagrama U vs Th proposto por Black et al. (1997), onde verifica-se a relação de linearidade entre as amostras e a razão Th/U proposta por Taylor \& McLennam (1985) como representando a crosta superior; Símbolos como na Fig. 3.

que os níveis de interação entre a crosta e a evolução dos magmas básicos foi baixa (Black et al. 1997), estando a diferenciação e evolução dos magmas dominantemente fundamentada na cristalização fracionada.

O conteúdo em ETR dos basaltos alcalinos apresenta variações entre as amostras com baixo e alto Ti-P. O conjunto baixo Ti-P apresenta o $\sum \mathrm{ETR}_{(1)}$ da ordem de 742 , gerando padrões próximo da horizontalidade para os ETRP materializados por uma razão $\mathrm{Gd} / \mathrm{Lu}_{(\mathrm{n})}$ média de 1.87 e valores de $\mathrm{Lu}$ (n) em torno de 15.9; as ETRL apresentam teores crescentes entre 40.06 a 293 em La ${ }_{(1)}$ com teor médio da ordem de 179,7. As anomalias negativas em európio são pouco significativas, com uma média de 
0.84 para a razão $\left(\mathrm{Eu} / \mathrm{Eu}^{*}\right)_{\mathrm{n}}$, concordando com os padrões descritos para basaltos alcalinos associados à panteleritos de outras regiões do mundo (Civetta et al. 1998). Destaca-se a presença de leves anomalias positivas em európio nos termos mais diferenciados, comuns a associações bimodais metaluminosasperalcalinas (Civetta et al. 1998) (Fig. 11a). Nos termos alto Ti-P destaca-se o aumento na média do $\sum \mathrm{ETR}_{(\mathrm{n})}$ que sobe para 1167 enquanto que a razão $\mathrm{Gd} / \mathrm{Lu}$ (n) passa para 2.25 com teor médio de $\mathrm{Lu}$ (n) de 20.8, formando um conjunto de ETRP homogêneo e levemente mais fracionado; o conjunto de ETRL apresenta o mesmo fracionamento dos baixo Ti-P, com uma inclinação para a razão $\mathrm{La} / \mathrm{Sm}$ de 3,54 e um teor médio de 276,5 para o $\mathrm{La}_{(11)}$. As anomalias em európio são pouco significativas, com razấo (Eu/Eu*) de 0.85, virtualmente igual aos baixo Ti-P (Fig $1 \mathrm{lb}$ ). A visualização dos dois conjuntos de padrões evidencia a semelhança na distribuição e um acréscimo nos valores dos ETR, formando um conjunto homogêneo de amostras que apontam para a similaridade das fontes e dos processos atuantes na geração dos magmas. A comparação entre os conjuntos baixo e alto $\mathrm{Ti}$ - $\mathrm{P}$ e os basaltos alcalinos provindos da Panteleria apresenta uma boa correlação, principalmente tendo em vista os baixos valores em ETRL e a presença de leves anomalias positivas em európio nas lavas baixo Ti-P.

As lavas riolíticas e intrusivas quartzo monzoníticas metaluminosas apresentam padrões muito semelhantes (Fig. 11c,d), destacando-se dos basaltos por um $\sum$ ETR levemente mais elevado, chegando a valores de 1480 nos riolitos, pelo fracionamento nas ETRL mais acentuado, com uma razão ( $\mathrm{La} / \mathrm{Sm})$ de 5,79 e por conterem anomalias em európio mais pronunciadas, com uma razão $\left(\mathrm{Eu} / \mathrm{Eu}^{*}\right)$ de 0.686 . Os riolitos apresentam os ETRP levemente mais elevados do que os quartzo monzonitos e mais próximos dos teores contidos nos basaltos.

ROCHAS PERALCALINAS COMENDÍTICAS - RPC No detalhamento geoquímico dos termos peralcalinos da Associação Vulcano-Plutônica Taquarembó utilizou-se os teores em Zr, Y, Hf, Ta e Th, por serem elementos traço normalmente enriquecidos em comenditos e panteleritos supersaturados, e que apresentam comportamento próprio e bem definido dentro de sequiências peralcalinas, sendo especialmente imóveis durante alterações pós eruptivas (MacDonald \& Bailey 1973). Segundo Watson (1979) a distribuição do $\mathrm{Zr}$ depende fortemente da composição molar de $\left(\mathrm{Na}_{2} \mathrm{O}+\mathrm{K}_{2} \mathrm{O}\right) / \mathrm{Al}_{2} \mathrm{O}_{3}$ contida no magma original, sendo condicionado secundariamente pela temperatura e teores de $\mathrm{SiO}_{2}$. Para magmas peraluminosos os níveis de saturação de Zr situam-se ao redor dos $100 \mathrm{ppm}$, sendo que em magmas peralcalinos, pelo aumento na solubilidade do $\mathrm{Zr}$, pode alcançar até cerca de $3,9 \%$ em peso nas rochas com razões $\left(\mathrm{Na}_{2} \mathrm{O}+\mathrm{K}_{2} \mathrm{O}\right) / \mathrm{Al}_{2} \mathrm{O}_{3}$ próximas a 2.0, teores compatíveis com os termos peralcalinos do Platô, onde os teores em $\mathrm{Zr}$ variam entre 0.6 a $1.1 \%$, para uma razão de alcalis/alumina de 0.65-0.75.

Como apontado por Schmincke (1974), as rochas peralcalinas tufáceas são provavelmente a melhor suíte para se documentar as propriedades físicas de magmas em relação a suas características químicas, sendo que algumas destas particularidades estão retratadas nos diagramas de distribuição do $\mathrm{Zr}$ vs elementos maiores e traço. Nestes diagramas, através de amostras coletadas no topo e na base de diferentes derrames, identificase um forte gradiente químico interno a cada fluxo de lava, constatando-se que, próximo a base de alguns derrames ocorrem teores muito mais elevados em $\mathrm{Zr}$ e $\mathrm{Y}$ do que no topo, imprimindo
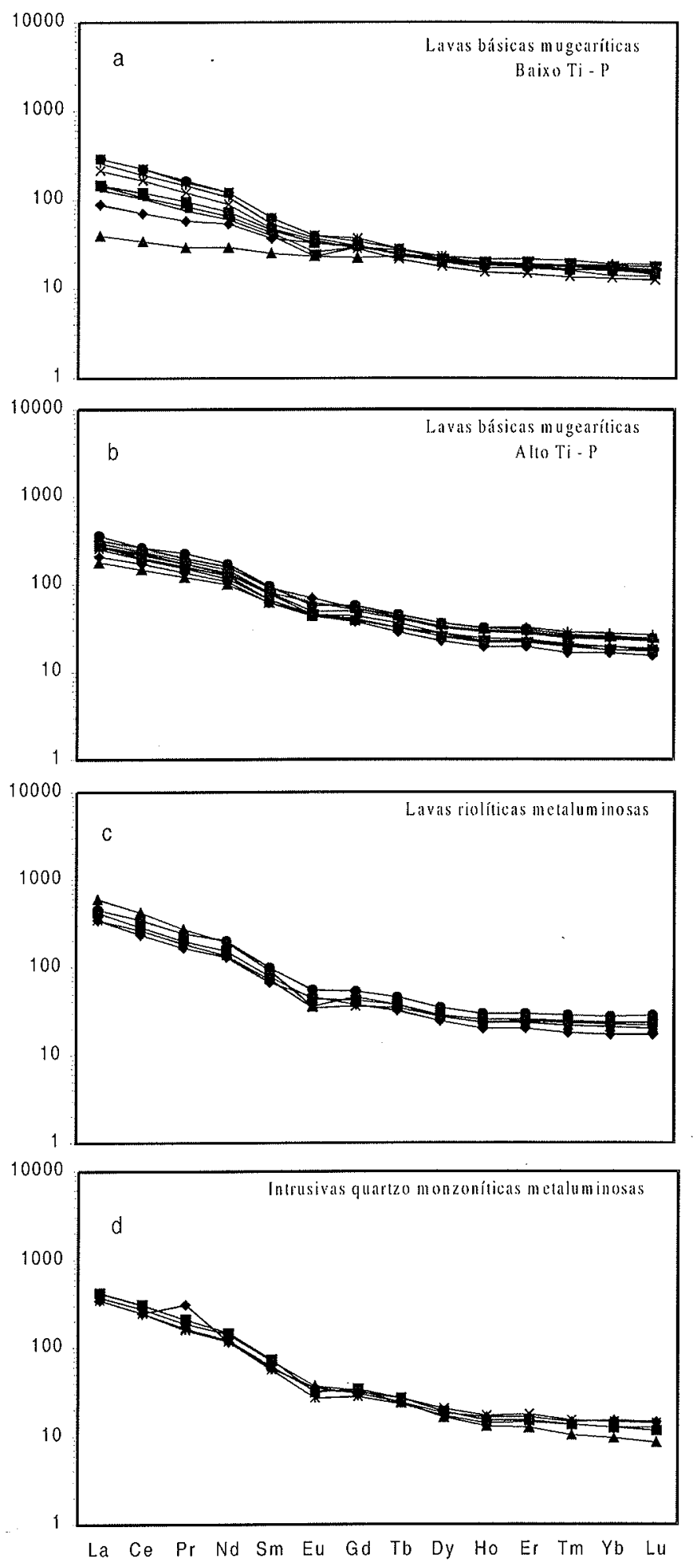

Figura 11 - Diagramas de ETR para: a - basaltos baixo Ti-P; $b$ basaltos alto Ti-P; $c$ - riolitos metaluminosos; $d$ - quartzomonzonitos.

uma heterogeneidade composi-cional entre os diferentes níveis de um mesmo evento eruptivo (Fig 6a). Essas variações provavelmente estão relacionadas as variações texturais decorrentes de segregações durante o fluxo de lavas, associado ao fluxo 
interno de voláteis e a processos de alteração sineruptivos, como sugerido por Bailey (1989), onde o aumento concomitante dos álcalis no sentido do topo, particularmente sódio, associase a concentrações preferenciais de voláteis, ficando os elementos mais compatíveis concentrados preferencialmente nas porções basais dos derrames.

Em magmas félsicos peralcalinos, como os formadores de panteleritos e comenditos, é possível o enriquecimento extremo em $\mathrm{Zr}$ (REE e Ta) relacionado ao fracionamento de feldspatos que geram a produção desses líquidos a partir de magmas predecessores não-peralcalinos. Watson (1979) e Leat et al. (1986) demonstram que os teores normais em $\mathrm{Zr}$ para magmas per-alcalinos são variáveis, comumente posicionados entre 350 a 500 ppm, sendo que a vasta maioria das rochas vulcânicas subalcalinas saturadas em sílica apresentam $\mathrm{Zr}<300$ ppm. Exceção é feita à rochas riolíticas relacionadas a ilhas oceânicas, podendo conter mais de $700 \mathrm{ppm}$ em $\mathrm{Zr}$ e que são estratigraficamente identificadas no registro geológico pela associação com grandes volumes de basaltos de ilhas oceânicas. Utilizando esta distribuição em $\mathrm{Zr}$ verifica-se que a AVPT apresenta um gap entre 500 e $650 \mathrm{ppm}$ em $\mathrm{Zr}$, onde as rochas metaluminosas apresentam teores entre 161 a $484 \mathrm{ppm}$, enquanto a peralcalina inicia ao redor de $643 \mathrm{ppm}$ e se estende até $1045 \mathrm{ppm} \mathrm{Zr}$.

Associações peralcalinas ou panteleríticas, são muito ricas em Ta, com elevadas razões Ta/Th, enquanto os comenditos, de menor alcalinidade, são mais pobres neste elemento (Hildreth 1981). Com base nas variações estipuladas em associações deste tipo, foi elaborado o diagrama Th $v$ s Ta contendo a distribuição das rochas peralcalinas do Platô (Fig. 12), onde se evidencia que as lavas peralcalinas apresentam uma razão Ta/Th entre 0.09-0.12 para todo o conjunto de amostras, concentrando-se ao longo do trend comendiítico. A distribuição dos pontos mostra estreita relação com os trends descritos em rochas

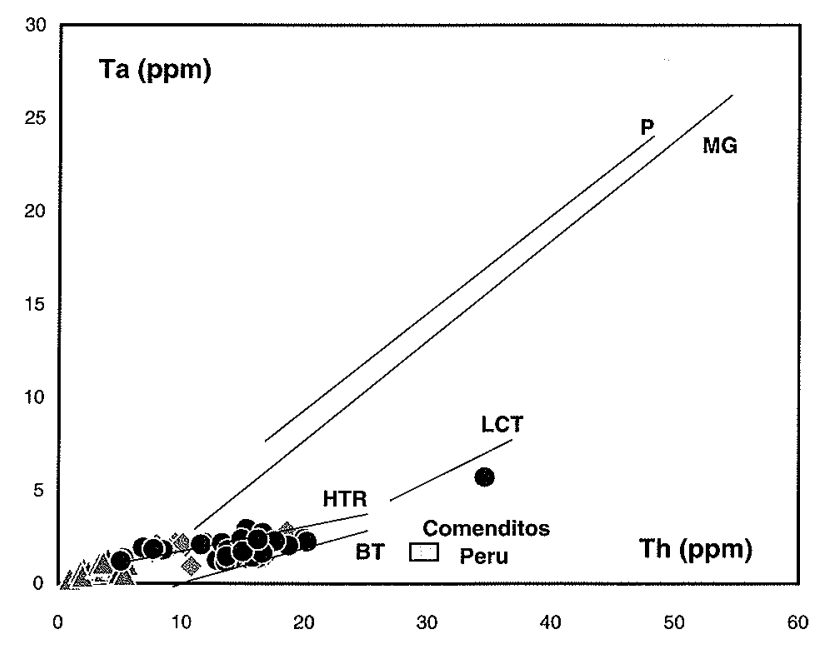

Figura 12 - Diagrama Ta vs Th contendo a distribuição dos pontos da SVPT e os trends descritos para rochas peralcalinas das sequiências de BT-Bishop Tuff na Califórnia; HTR Huckle Berry Ridge Tuff; LCT- Lava de Creek Tuff de Yellowstone e a média de comenditos do Peru, retirados de Brown et al. (1984). Símbolos como na Fig. 3. peralcalinas da sequiência de Bishop Tuff na Califórnia, de Huckle Berry Ridge Tuff, das Lava de Creek Tuff de Yellowstone ou da média de comenditos do Peru, contraposto ao claro afastamento dos trends panteleríticos obtidos na região da Pantelleria e do Kenya, expresso no diagrama modificado de Leat et al. (1986).

Segundo MacDonald (1974), definem-se três grandes classes de rochas vulcânicas peralcalinas supersaturadas, a- as relacionadas a ilhas oceânicas e que apresentam uma razão $\mathrm{Zr} /$ $\mathrm{Nb}<10$ e onde predominam comenditos e traquitos comendíticos em detrimento aos panteleritos; $\mathbf{b}$ - rochas vulcânicas relacionadas a rifts continentais, onde traquitos e panteleritos são dominantes, podendo ocorrer comenditos e onde todas as rochas apresentam uma razão $\mathrm{Zr} / \mathrm{Nb}<10$; e c-rochas vulcânicas peralcalinas relacionadas a zonas de subducção, com razões $\mathrm{Zr}$ l $\mathrm{Nb}>10$. Estas, predominantemente comendíticas, ocorrem em ar$\cos$ de ilhas ou sobre margens continentais ativas, estando normalmente acompanhadas de associações calcicoalcalinas médio a alto-K. As altas razões $\mathrm{Zr} / \mathrm{Nb}$ das rochas vulcânicas ácidas peralcalinas do platô do Taquarembó, com teores em $\mathrm{Zr}$ cerca de 15 vezes maiores que os de $\mathrm{Nb}$, são próprias de associações litológicas relacionadas a margens continentais ativas ou de ambientes pós-colisionais, posicionadas acima de zonas de subducção, cuja influência também é sugerida pelas fortes anomalias negativas em $\mathrm{Nb}$-Ta presentes nos espectros normalizados aos valores MORB (Fig. 14).

Os trends peralcalinos comendíticos também podem ser obervados em diagramas de ETR, os quais apresentam padrões homogêneos (Fig.13a). Nas lavas riolíticas o $\sum E T R$ médio é de 2604 , com valores de ETRPs baixos e distribuiçăo horizontal, com razão $(\mathrm{Gd} / \mathrm{Lu})_{11}$ de 1.62, mais baixa do que a dos basaltos alcalinos. Destacam-se os elevados valores em ETRL em relação aos ETRP, conformando uma curva que inicia com teores de $\mathrm{La}_{(1)}$ entre 750 e 1340 e razão $(\mathrm{La} / \mathrm{Lu})_{11}$ média de 15.30 . As anomalias negativas em Eu são proeminentes, cujo valor médio de $\left(\mathrm{Eu} / \mathrm{Eu}^{*}\right)_{11}=0.246$. Estas anomalias são inversamente proporcionais aos valores em ETRL mostrando que, em linhas gerais, quanto mais alta a razão $\mathrm{La} / \mathrm{S} m$ maiores as anomalias de $\mathrm{Eu}$, chegando a teores de La(n) da ordem de 1340 e anomalias $\left(\mathrm{Eu} / \mathrm{Eu}^{*}\right)$ de 0.08 . Os sienitos peralcalinos apresentam $\sum E_{(n)}$ de 2690 , semelhante aos padrões obtidos em riolitos peralcalinos (Fig. 13b), com anomalias em Eu da ordem de 0.614, menores que a das lavas comendíticas e com distribuição de ETRP muito próxima a das lavas peralcalinas, com razão (Gd/Lu) de 1.957. Os padrões obtidos nas intrusões sieníticas e nas lavas comendíticas assemelham-se aos dos traquitos comendíticos descritos na região da Panteleria por Civetta et al. (1998). Os autores propõem que processos de diferenciação estejam retratados nas concentrações crescentes do åETR, no leve acréscimo em ETRL em relação aos ERTP, ao acréscimo na razão (La/ Lu) e ao desenvolvimento de anomalias de Eu progressivamente maiores, devido ao dominante fracionamento de feldspatos.

A comparação dos diagramas de ETR das associações litológicas alcalinas metaluminosas e peralcalinas que compõem a Associação Vulcano-Plutônica Taquarembó, com as rochas da suíte vulcânica de Trans-Pecos, constituída por traquitos, quartzo-traquitos e riolitos peralcalinos, sotopostos e sobrepostos por vulcânicas máficas que variam entre hawaiitos a mugearitos (Parker 1983), mostra fortes semelhanças, salientando-se, em ambos os casos, um enriquecimento substancial no 


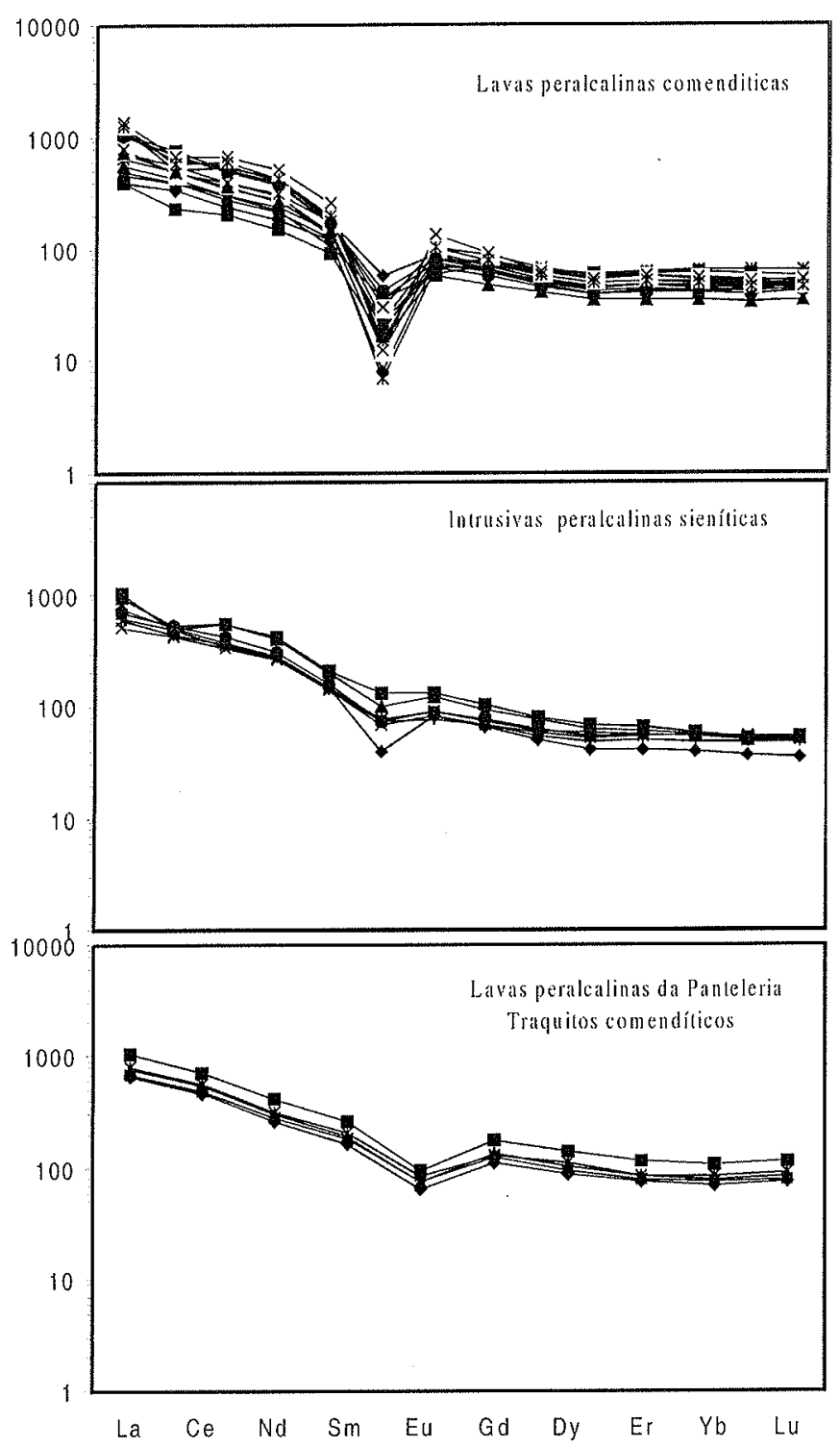

Figura 13 - Diagramas de ETR para: a-lavas peralcalinas comenditicas; $b$ - intrusivas peralcalinas sieniticas; e c-lavas peralcalinas da Panteleria.

¿ETR dos comenditos em relação aos mugearitos, o desenvolvimento de anomalias negativas de Eu nos termos comendíticos e anomalias (Eu/Eu*) médias de 0.24 . Na região de TransPecos, Parker (1983) sugere que o comportamento dos ETR está relacionado à cristalização fracionada envolvendo cerca de $70 \%$ de feldspatos no total de minerais fracionados, para produzir um líquido comendítico a partir de uma composição mugearítica. Esta estimativa é afetada no magmatismo submetido a fracionamento de apatita previsto nos termos ricos em $\mathrm{SiO}_{2}$.

PETROGÊNESE A petrogênese de magmas peralcalinos e alcalinos metaluminosos saturados em sílica tem sido motivo de grandes debates petrológicos (e.g. Smith et al. 1977, Parker 1983, Black et al. 1997, Johnson et al. 1989), nos quais tem sido levantadas diversas hipóteses genéticas para estes tipos de ma- gmas. Bonin (1982) sintetiza o problema em duas hipóteses essenciais resumidas como: a- geração de magmas alcalinos por diferenciação (cristalização fracionada) a partir de magmas parentais básicos -hipótese baseada na frequiente presença de basaltos levemente alcalinos associados à rochas peralcalinas; e b- geração de magmas alcalinos a partir da fusão parcial de diferentes porções da crosta superior e inferior por anatexia local. A anatexia inicia com a distensão da crosta, que gera uma queda de pressões e conseqüente concentração de fluídos e focalização da energia termal, acompanhado de recargas episódicas do sistema por magma básico. Estas duas hipóteses, segundo o autor, podem ser combinadas na tentativa de uma origem mista para magmas ácidos, onde líquidos peralcalinos seriam derivados diretamente do manto, enquanto os metaluminosos resultariam da contaminação dos líquidos peralcalinos originais por fusão parcial da crosta superior. Uma variedade de processos ígneos deve ser adicionada a cada uma destas hipóteses, pois a cristalização fracionada, convecção e mistura de magmas gerada por recarga, filtragem por pressão, assimilação de diferentes frações de crosta e os causados por fluxo de voláteis, tem demonstrado a sua importância na evolução de diferentes suítes magmáticas.

Basaltos posicionados em porções internas de placas, quando comparados ao MORB, apresentam-se enriquecidos na maioria dos elementos incompatíveis, cuja extensão pode ser expressa através de diagramas multielementares (Pearce 1982). Comparando-se por estes diagramas as litologias dos termos alcalinos metaluminosos e alcalinos comendí́ticos do Platô (Fig. 14), verificam-se a existência de dois trends evolutivos, divididos entre as litologias metaluminosas e peralcalinas, ambos originados a partir de composições basálticas. O grau de enriquecimento em elementos incompatíveis entre os basaltos baixo e alto Ti-P é semelhante, porém elementos como $\mathrm{TiO}_{2}, \mathrm{Y}$ e $\mathrm{Yb}$ mostram variações em relação ao MORB, com valores levemente mais baixos ao MORB para os baixo Ti-P e levemente acima para os alto Ti-P. Os elementos incompatíveis de maior raio iônico, como Rb, Ba, The Ce mostram-se enriquecidos, destacando-se uma anomalia negativa em Ta- $\mathrm{Nb}$, cuja presença normalmente esta relacionada a associações de rochas posicionadas acima de zonas de subducção, resultando em padrão humped (Pearce 1982), característico de basaltos internos a placa e gerados a partir de manto enriquecido e posicionado acima de zonas de subducção, posição esta reforçada pelas anomalias negativas de Ti. Altas concentrações em $\mathrm{Hf}$ e $\mathrm{Zr}$ em relação a $\mathrm{Y}$ e $\mathrm{Yb}$ apontam um enriquecimento relativo destes elementos no manto, indicando que os reservatórios relacionados a AVPT estariam provavelmente posicionados próximo ao manto superior.

Nos termos sieníticos metaluminosos ressaltam os baixos teores em $\mathrm{Sr}$, provavelmente relacionado ao fracionamento de plagioclásio, o início de uma anomalia negativa de $\mathrm{P}_{2} \mathrm{O}_{5}$, resultante do fracionamento de apatita e a manutenção dos teores de $\mathrm{TiO}_{2}$, Y e Yb. Nos sienitos peralcalinos os teores de Sr mantémse próximos aos dos basaltos alto Ti-P, que são fracionados conformando anomalias negativas, enquanto que $\mathrm{Y}$ e $\mathrm{Yb}$ estão enriquecidos juntamente com os demais elementos litófilos de elevado potencial iônico (HFS). No extremo riolítico, os termos metaluminosos mantém o $\mathrm{Sr}$ ao mesmo nível dos sienitos, acentuando levemente as anomalias em $\mathrm{P}_{2} \mathrm{O}_{5}$ e $\mathrm{TiO}_{2}$ e uma anomalia positiva em $\mathrm{Ce}$, enquanto que nos peralcalinos há um fracionamento substancial do $\mathrm{Sr}$ e o aparecimento de forte anomalia 

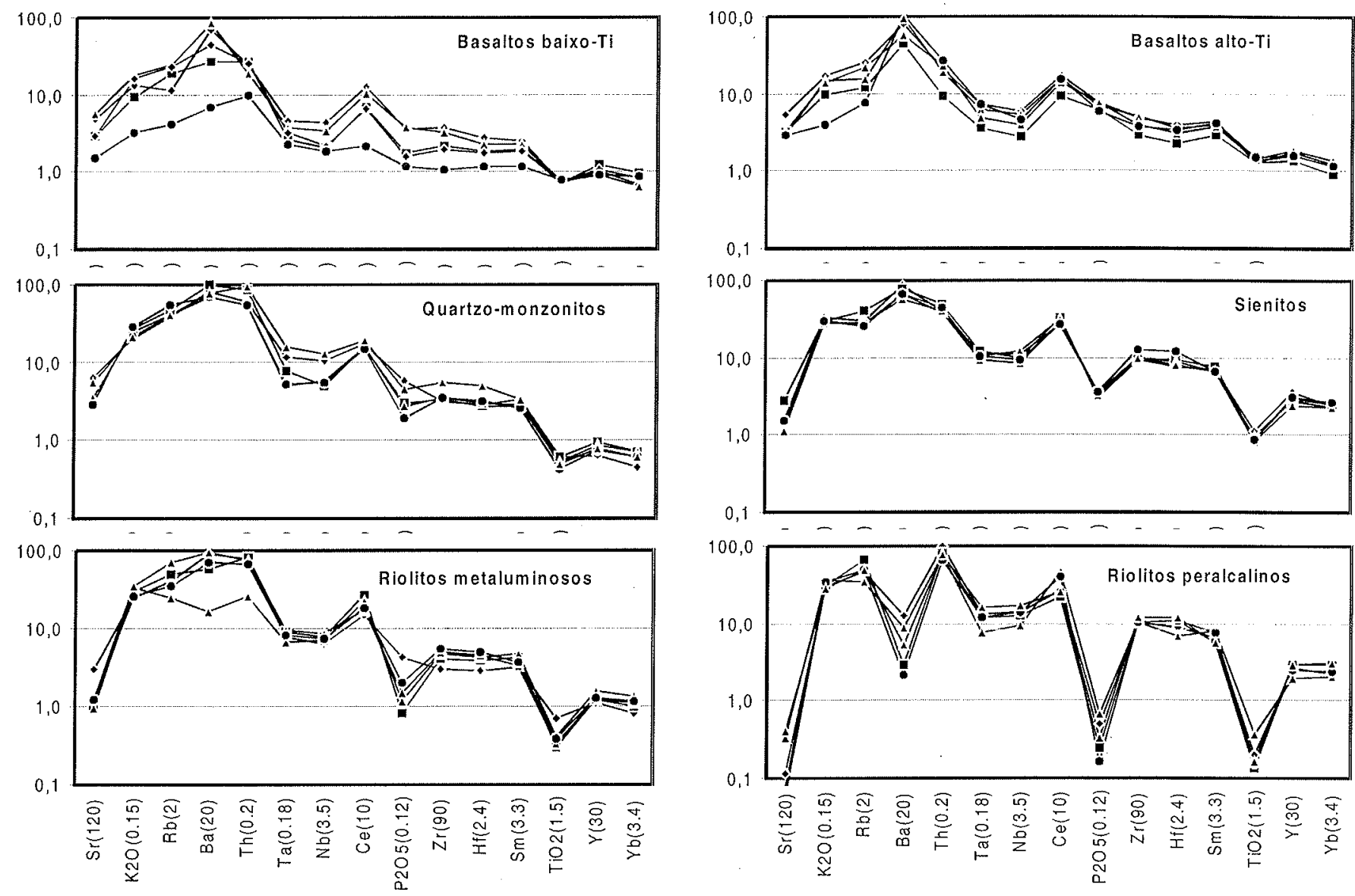

Figura 14 - diagramas multielementares normalizados ao MORB comparando as litologias que compõem as associações: aalcalina metaluminosa-RAM e b-alcalina comendilitica-RPC aflorantes no Platô, conforme Pearce (1982).

negativa em $\mathrm{Ba}$, provavelmente relacionados ao fracionamento de feldspatos, acentuando as anomalias de $\mathrm{P}_{2} \mathrm{O} 5$ e $\mathrm{TiO}_{2}$, provavelmente devido ao maior grau de diferenciação e ao fracionamento de óxidos de Fe-Ti e apatita. Comparando as distribuições entre elementos incompatíveis das rochas do Platô com os dados descritos por Leat et al. (1986) para a suíte bimodal de Snowdonia, constituída por basaltos alcalinos e comenditos, verifica-se a estreita relação entre as litologias constituintes de ambas as associações, tanto entre os termos basálticos quanto riolíticos. Estes autores descrevem as características físico-químicas do magmatismo responsável pela geração da suíte de Snowdonia como relacionado ao armazenamento de magmas em câmaras posicionadas a altos níveis da crosta, constituídas por magmas riolíticos sobrepostos a basaltos.

Bohrson \& Reid (1997) estudando a gênese de vulcânicas peralcalinas associadas a basaltos alcalinos da região de Socorro Island, no México, admitem que a existência de gaps ṇa distribuição de elementos maiores como $\mathrm{SiO}_{2}$ e $\mathrm{K}_{2} \mathrm{O}$, com teores em HFSE como $\mathrm{Zr}$, Nb e Hf virtualmente iguais, é incompatível com a origem de traquitos peralcalinos a partir de basaltos alcalinos por cristalização fracionada, colocando como alternativa razoável a fusão parcial de rochas máficas intrusivas. Por outro lado, dados de elementos menores e traços são compatíveis com a geração de riolitos peralcalinos a partir de magma parental com composição traquítica, por fracionamento de uma assembléia mineral dominada por feldspatos alcalinos. As anoma- lias negativas em Eu, presentes do extremo comendí-tico da AVPT, estão de acordo com modelos de fracionamento envolvendo grande quantidade de feldspatos, a partir de líquidos parentais intermediários.

A integração dos dados obtidos para as rochas do Platô do Taquarembó, cuja composição varia desde basaltos alcalinos (mugearíticos) alto e baixo Ti-P, riolitos metaluminosos, quartzomozonitos, até comenditos e sienitos, sugere que as rochas vulcânicas básicas representem magmas parentais, produto de diferentes graus de fusão parcial de fontes mantélicas. Admite-se que sob o principal controle da quantidade de voláteis retida na fonte, ocorreram extrações de mais baixa temperatura e maior quantidade de fusão, resultando em magmas primários com mais baixos teores de elementos incompatíveis de alto potencial iônico, relacionado aos termos metaluminosos, enquanto que os basaltos alto Ti-P representam menores taxas de fusão sob menor atividade de voláteis e mais altas temperaturas, evoluindo por fracionamento mineral até líquidos comendí́ticos.

A região fonte dos magmas parentais básicos é interpretada como do tipo EM1, por suas características composicionais de elementos traços e isótopos, implicando em prévio matassomatismo causado por subducção crustal, como sugerido por Hart (1988), com a presença de um importante componente pelágico indicado pelo elevados valores de $\mathrm{Ba}$ (Weaver 1991). O intervalo temporal entre o evento de subducção e a geração deste magmatismo é de dificil determinação, uma vez que varia- 
ções composicionais assim produzidas no manto podem ser preservadas por um longo período de tempo (Wyllie 1994). As variações composicionais dos magmas parentais em direção aos derivativos mais evoluídos podem, na maior parte das vezes, ser explicadas por cristalização fracionada, tanto para os elementos traço como maiores. O mecanismo de diferenciação envolveu cristalização fracionada em sistema fechado, cuja recorrência temporal sugere recarga da câmara magmática por magmas basálticos derivados do manto. A redução progressiva dos efeitos metassomáticos provocados pela subducção, associada à contribuição da litosfera sub-continental interna a placa produziria magmas, derivados do manto, contendo níveis crescentes de HFS, entre os quais o Nb, Ta, Hf, Yb, Y, Ga, Zr, Th e $\mathrm{Ce}$ e decrescentes em $\mathrm{Ti}, \mathrm{P}$ e $\mathrm{Sr}$, como apontam Pearce et al. (1984) e Förster et al. (1997), características que concordam com os dados geoquímicos desta Associação Vulcano-Plutônica Taquarembó.

POSICIONAMENTO TECTÔNICO Suítes vulcanoplutônicas bimodais constituídas por associações de basaltos alcalinos a riolitos peralcalinos tem sido descritas em vários ambientes tectônicos, Macdonald (1974) e Civetta et al. (1998), sendo que as mais significativas encontram-se em regiões continentais não orogênicas, submetidas a domeảmento e/ou rifteamento crustal, como o Complexo Vulcânico de Itcha no território de British Columbia - Canadá (Charland, Francis \& Ludden 1993), no Grande Rift do Kenya - África (Black et al. 1997), ou na ilha da Pantelleria - Itália (Civetta et al. 1998), enquanto que ocorrências menos expressivas tem sido descritas, em ilhas oceânicas posicionadas sobre cadeias de espalhamento de fundo oceânico, como na região de Socorro Island, junto a costa do pacífico no México (Bohrson \& Reid 1997) ou o Complexo Vulcânico de Thverartindur da Islândia (Soesso 1997), ou em regiões relacionadas a arcos de ilhas, como no arco vulcânico de Taupo na Nova Zelândia, representado pelo vulcanismo de Major Island (Weaver et al. 1990). Descrições de suítes bimodais alcalinas a peralcalinas relacionadas a áreas de tectônica extensional, geradas durante estágios finais de cinturões orogênicos, são ainda restritas, sendo que algumas das mais importantes se posicionam na região de Parys Mountain Volcanics, cinturão orogênico Caledoniano (Leat et al. 1986), ou na região de Lachland Fold Belt, sudeste da Austrália (Collins et al. 1982).

Para a definição entre ambientes tectônicos foram selecionados aqueles ambientes geradores de magmas a semelhança dos encontrados no Platô, utilizando diagramas discriminantes como os propostos por Ewart (1979), Pearce et al. (1984), Leat et al. (1986) Förster et al. (1997). Dentre estes, Pearce et al. (1984) propuseram a principal sistemática de integração entre a composição química dos magmas e seu posicionamento tectônico, definindo quatro tipos de magmatismo e sua relação com ambientes tectônicos, discriminados entre: a- magmas de cadeias oceânicas - org; b- de arcos vulcânicos - vag, c- intraplaca - wpg; e d- de regiões colisionais - colg, sendo relacionados a fontes mantélicas, crustais e mistas. Empregando os parâmetros propostos por aqueles autores, expressos pela relação $\mathrm{Rb}$ vs $(\mathrm{Yb}+\mathrm{Nb})$, somado a sugestão de um percurso evolutivo que vincula a fonte ao posicionamento tectônico (Fig. 15) verificase a transposição dos limites dos campos de arco vulcânico em direção ao das associações de rochas intraplaca. O ambiente

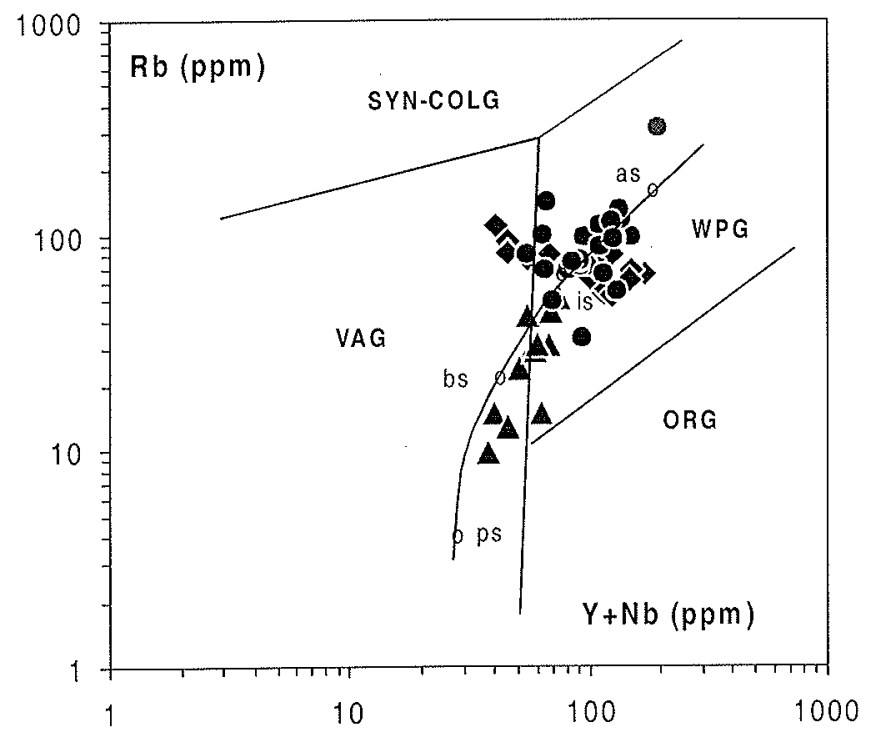

Figura 15 - Diagrama $R b$ vs $(Y+N b)$ discriminante de ambiente tectônico (Pearce et al. 1984) com a distribuição dos pontos da AVPT em direção a posições de crosta estável. Símbolos como na Fig. 3. Para os pontos ps, bs, is e as, consultar o texto.

intraplaca e o seu carater pós-orogênico e pós-colisional também é indicado pelas relações tectônicas de campo e características geocronológicas. Assim como Förster et al. (1997), extraise uma primeira constatação, a de que suites de rochas não apresentam um posicionamento tectônico estático, mas podem migrar no tempo e no espaço para ambientes transicionais entre si, e que, durante sua evolução, os magmas não são sistemas isolados, mas adaptáveis às condições reinantes em cada nova etapa, como normalmente ocorre em regiões orogênicas. Como consequiência desta evolução, ocorre uma mistura potencial entre diferentes proporções das áreas fontes relacionadas ao desenvolvimento das câmaras magmáticas, resultando em overlap entre as linhas divisórias propostas nos diagramas discriminantes de definição de ambiente tectônico. As interações de magmas com o meio circundante podem ser seguidas de assimilação e cristalização fracionada, gerando transições que representam uma mistura em diferentes proporções de todos os fatores atuantes durante processo de geração e posicionamento dos magmas. Neste mesmo diagrama, os pontos ps,bs, is e ac ilustram o produto de um modelo petrogenético ideal de geração de magmas (Thompson et al. 1982, Pearce et al. 1984), em posição interna à placa, derivado de fonte mantélica enriquecida em elementos incompatíveis em relação a composição média do manto, sendo derivado por fusão parcial de cerca de $15 \%$ de uma fonte primária, deixando um resíduo aproximado de $\mathrm{Ol}{ }_{67-5} \mathrm{Opx}$ ${ }_{22-5} \mathrm{Cpx}{ }_{10}$. A cristalização fracionada deste magma primário, envolvendo olivina, piroxênio, plagioclásio \pm magnetita e anfibólio pode gerar composições de magmas com teores relativamente elevados em $\mathrm{Rb}$ e $(\mathrm{Nb}+\mathrm{Y})$. Este modelo baseia-se na suíte de Skye, sendo admitida a combinação de assimilação e fracionamento entre os pontos ps-bs a partir da interação de frações de crosta com magma básico-ultrabásico, passando a sistema de critalizaação fracionada fechado para explicar as variações entre os pontos bs-is e entre is-as. Neste esquema nota-se que, além 
de uma composição pouco usual do manto, é necessário um estágio inicial de assimilação de crosta para explicar a seqüiência evolutiva. Tendo em vista o afastamento das amostras estudadas em relação ao limite composicional de magmas sin-colisionais, acompanhado pelos baixos teores em $\mathrm{Rb}$ e $\mathrm{Ta}$, reduzem-se as possibilidades de contribuição de frações de rochas sedimentares durante a evolução dos magmas.

Na confrontação entre o posicionamento tectônico e a indicação de fontes de magmas, é sempre conveniente a utilizar diagramas que empreguem elementos que não sujeitos aos efeitos de fusões parciais e cristalização fracionada, ou que tenham suas modificações atenuadas. Assim, optou-se pelo diagrama de Pearce (1984), que utiliza o Yb como fator de normalização do Th e Ta, e que permite definir fontes de magma do tipo MORB ou WPB em campos bem delimitados, mesmo que suítes vulcânicas extraídas destas fontes tenham sido contaminadas por crosta continental. A distribuição dos pontos da AVPT neste espaço (Fig. 16) insere-se integralmente no campo das rochas relacionadas a arcos vulcânicos, corroborando os resultados obtidos pelos diagramas discriminantes de posicionamento tectônico.

A composição química apresentada pela AVPT, quando comparada, no diagrama $\mathrm{Zr} v s \mathrm{Nb}$ (Leat et al.1986), a outras suítes vulcano-plutônicas bimodais também posicionadas sobre margens continentais ativas, apresenta um trend paralelo à linha de razão $\mathrm{Zr} / \mathrm{Nb}=10$, descrita por Ewart (1979) e modificada por Leat et al. (1986), como representativa de suítes peralcalinas orogênicas, sendo comparáveis às suítes vulcânicas das regiões de Snowdonia e Devine Canyon Tuff, de cinturão Caledoniano, e interpretadas com típico magmatismo alcalino posicionado acima de uma zona de subducção.

Para a associação vulcano-plutônica do Platô do Taquarembó propõe-se assim a produção de magmas em um ambiente intraplaca pós-colisional, com proveniência dos magmas primários de fontes afetadas por prévia subducção litosférica.

CONCLUSÕES O platô vulcânico do Taquarembó esta constituído por uma Associação Vulcano-Plutônica Bimodal representada por dois conjuntos litológicos: um composto por basaltos alcalinos, riolitos metaluminosos e intrusivas quartzo monzoníticas (Rochas Alcalina Metaluminosa - RAM); e um segundo composto basaltos mugearíticos, riolitos peralcalinos comendiúticos e intrusivas sieníticas (Rochas Peralcalina Comendítica-RPC).

A presença de magmatismo alcalino básico relacionado a unidade cartografada no escudo Sul-Riograndense como Formação Acampamento Velho, sensu Horbach et al. (1986) leva à sugestão de que este magmatismo seja redefinido regionalmente, passando a ser constituído por uma associação vulcanoplutônica bimodal.

O paralelismo dos padrões de elementos incompatíveis, ressaltando a semelhança das razões de elementos geoquimica-

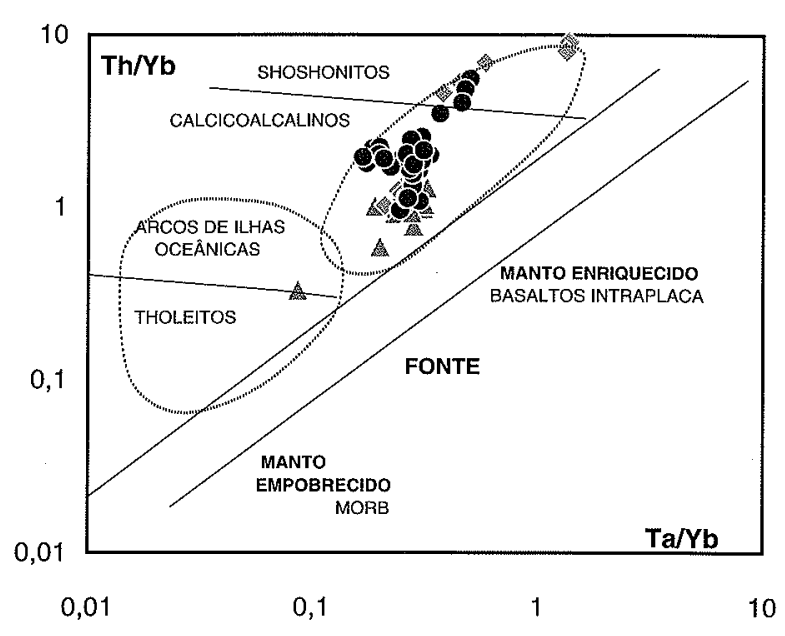

Figura 16 - Diagramas $T h / Y b$ vs $\mathrm{Ta} / \mathrm{Yb}$ discriminante de ambiente geotectônico mostrando a relação da AVPT com uma fonte mantélica enriquecida e rochas geradas ao longo de margens continentais ativas (Pearce 1983).

mente similares, como o $\mathrm{Nb} / \mathrm{Ta}, \mathrm{Zr} / \mathrm{Hf}, \mathrm{Y} / \mathrm{Yb}$, para os basaltos baixo Ti-P e os mais ricos em álcalis, com alto Ti-P, sugerem que ambos provem da mesma fonte. O enriquecimento em elementos incompatíveis dos basaltos alto Ti-P pode refletir menores proporções de fusão parcial, decorrentes de menores atividades de voláteis em locais ou momentos diversos, na mesma porção do manto, previamente metassomatizado.

A fonte do magmatismo que gerou o conjunto de rochas metaluminosa é o manto enriquecido, composicionalmente próximo do tipo EMl, como indicam os dados isotópicos e de elementos traço. Os teores elevados de Ba sugerem uma contribuição pelágica no material contaminante da fonte mantélica, fortalecendo a hipótese de subducção litosférica oceânica em detrimento a de delaminação litosférica.

As rochas vulcânicas e plutônicas félsicas são derivadas desse magma básico via processos de cristalização fracionada, em sistema sem influências externas substanciais, cuja recorrência temporal sugere recarga de câmara magmática por magmas basálticos derivados do manto.

O magma precursor da Associação Vulcano-plutônica do Taquarembó foi gerado em ambiente intraplaca, pós-colisional, com proveniência a partir de fontes tipo EMI originalmente empobrecidas e afetadas subsequientemente por processos de subducção litosférica.

Agradecimentos Aos revisores da RBG pelas sugestões ao manucsrito.

\section{Referências}

Almeida D.P.M., Zerfass H., Lima L. 1998. Estratigrafia das rochas vulcânicas da Formação Acampamento Velho (Meso-Cambriano a Eo-Ordoviciano) na região dos Cerros do Bugio e Perau (Caçapava do Sul, RS-Brasil). In: Congr. Uruguayo de Geol., 2, Anais.
Almeida F.F.M. de 1949. Novo campo de riolitos e tufos no sul do Brasil. Mineração, Metalurgia, 14:101-103

Almeida F.F.M. de, Hasui Y., Brito Neves B. B., Fuck R.A. 1991 Brazilian structural provinces: an introduction. Earth-Science Reviews, 17:1-29. 
Bailey M.M. 1989. Revisions to stratigraphic nomenclature of the Picture Gorge Basalt Subgroup, Columbia River Basalt Group. Geological Society of America, Special Paper, n. 239, p.67-84.

Black S., Macdonald R., Kelly M.R. 1997. Crustal origin for peralkaline rhyolites from Kenya : eviedence from U-Series Disequilibria and Th-Isotopes. J. Petrol., 38:277-297.

Bohrson W.A. \& Reid M.R. 1997. Genesis of Silicic Peralkaline Volcanic Rocks in na Ocean Island Setting by Crustal Melting and Open-system Processes: Socorro Island, Mexico. J. Petrol., 38:1137-1166.

Bonin B. 1982. Ring Complex Granites and Anorogenic Magmatism. Department os Petrology. Paris : Université Pierre et Marie Curie/ North Oxford Academic. 189p.

Brito Neves B.B. \& Cordani U.G. 1991. Tectonic evolution of South America during the Late Proterozoic. Prec. Res., 53:23-40.

Charland A., Francis D., Ludden J. 1993. Stratigraphy and geochemistry of the Itcha Volcanic Complex, Central British Columbia. Can. J. Ear. Sci., 30:132-144.

Chemale F., Wildner W., Fernandes E.L., Van Schmus R.W. 1999. Isotopic Studies of Brasiliano Retro-Arc Magmatism in Southern Brazil. In: SBG, Simp. Vulcanism. e Ambien. Associados, 1,Gramado, RS, Boletim de Resumos...

Civetta L., D'antonio M., Orsi G., Tilton G.R. 1998. The Geochemistry of Volcanic Rocks from Pantelleria Island, Sicily Channel : petrogenesis and characteristics of the mantle source region. J. Petrol., 39:1453-1491.

Collins W.J., Beams S.D., White A.J.R., Chappell B.W. 1982. Nature and Origin of A-Type Granites with Particular Reference to Southeastern Australia. Contr. Mineral. Petrol., 80:189-200.

Ewart A. 1979 A review of the mineralogy and chemistry of Tertiary_Recent dacitic, latitic, rhyolitic and related salic volcanic rocks. In: Barker F. (ed.) Trondjemites, Dacitic and Related Rocks. Elsevier, Amsterdam, 13-121.

Förster H.J., Tischendorf G., Trumbull R. B. 1997. An evaluation of the $\mathrm{Rb}$ vs. $(\mathrm{Y}+\mathrm{Nb})$ discrimination diagram to infer tectonic setting of silicic igneous rocks. Lithos, 40:261-293.

Fragoso-Cesar A.R.S., Machado R., Sayeg H.S., Fambrini G.L. 1992. Bacias orogênicas do ciclo brasiliano no Rio Grande do Sul e Uruguai. In : Workshop sobre as Bacias Molássicas Brasilianas, 1, pp.: 47-53.

Gastal M.C.P. 1997. Aspectos mineralógicos do Complexo Anelar Leões (CAL), Platô do Taquarembó, extremo sul do Brasil. In: SBGq, Semana de Geoquímica, 10, Congr. Geoquim. Países de Língua Portuguesa, 4 , Braga, Portugal, Actas... s.l . : s.n. p.5154.

Gastal M.C.P. \& Nardi L.V.S. 1998. The alcalic and shoshonitic intrusives in the region of the Taquarembó Plateu, southern Brazil: are they genetically related? In: Internat. Simp. Granites and Associated Mienralizations, 2, Extended Abstract Vol., p. 118120.

Hart S.R. 1988 Hetrogeneous mantle domains: signatures, genesis and mixing chonologies. Eath Planet. Sci.Lett., 90:273-296.

Hartmann L.A. 1998. Deepest exposed crust of Brazil - geochemistry of Paleoproterozoic depleted Santa Maria Chico granulites. Gondw. Res., 1:331-341.

Hildreth 1981. Gradients in silicic magmachambers: implications for lithospheric magmatism. Jour. Geoph. Res., 86:153-192.

Horbach R., Kuck L., Marimon R.G., Moreira H.L., Fuck G.F., Moreira M.L.O., Marimon M.P.C., Pires J.L., Vivian O., Marinho D.A., Teixeira W. 1986. Geologia. In: Folha SH.22 Porto Alegre e parte das folhas SH.21 Uruguaiana e SI.22 Lagoa Mirim. Rio de Janeiro : IBGE. p. 29-312. (Levantamento de Recursos Minerais, 33).

Johnson C. M., Czamanske G.K., Lipman P.W. 1989. geochemistry of
Intrusive Rocks Associated with the Latir Volcanic Field, New Mexico, and Contrasts Between Evolution of Plutonic and Volcanic Rocks. Contr: Mineral. Petrol., 103:90-109.

Jost H. 1984. Sedimentação e vulcanismo durante o Ciclo Brasiliano no Rio Grande do Sul: uma revisão. In: SBG, Congr. Bras. Geol., 33, Rio de Janeiro, Anais..., pp. 324 I-3257.

Kuno H. 1968. Differentation of Basalt Magma. 2. ed. New York, Jonh Wiley, pp. 623-688.

Le Bas M.J., Le Maitre R.W., Streickeisen A., Zanettin B. 1986. A chemical classification of volcanic rocks based on the total alkalisilica diagram. Jour: Petrol., 27:745-750.

Leat P.T., Jacson S.E., Thorpe R.S., Stillman C. J. 1986. Geochemistry of bimodal basalt-subalkaline/peralkaline rhyolite provinces within the Southern British Caledonides. Geol. Soc. London, 143:259-273.

Lima E.F. \& Nardi L.V.S. 1998. The Lavas do Sul shoshonitic assocuastion : implications for the origin and evolution of Noproterozoic shoshonitic magmatism in the southernmost Brazil. J. South Am. Ear. Sci., 11:67-77.

Lopes R.C., Wildner W., Sander A., Camozzato E. 1999. Alogrupo Guaritas: Aspectos Gerais e Considerações Sobre O Posicionamento do Vulcanismo Rodeio Velho (Encerramento do Ciclo Brasiliano ou Intalação da Bacia do Parana?). In: SBG, Simp. Vulcanism. Ambient. Assoc., 1, Gramado, RS, Boletim de Resumos...

MacDonald R. \& Bailey D.K. 1973. The chemistry of the peralkaline oversaturated obsidians, U.S.G.S. Prof. Paper, 440-N-1, p. 1-37.

MacDonald R. 1974. Nomenclature and petrochemistry of the peralkaline oversaturated extrusive rocks. In: D.K. Bailey, F. Barberi, R. MacDonald (Eds.) Oversaturated Peralkaline Volcanic Rocks. Bull. Volcanol. (Special Issue), 38:498-516.

Mau H. 1959. Ignimbritos na região de Caçapava do Sul, RS. Engenharia, Mineração, Metalurgia, 29:13-40.

Nardi L.V.S \& Lima E.F. 1985. A associação shoshonítica de Lavras do Sul, RS. Rev. Bras. Geoc, 15:139-146.

Paim P.S.G., Lopes R.C., Chemale Jr. F. 1995. Stratigraphic framework and depositional systems of the Camaqua Basin (Upper Vendian to Lower Ordovician) of southern Brazil. In: Centennial Conference 1895-1995, University of Stollenbosch, Abstracts..., pp. 35-37.

Paim P.S.G., Lopes R.C., Chemale Jr. F. 1999. Sistemas deposicionais e evolução paleogeográfica da Bacia do Camaquã (Vendiano superior a Ordoviciano inferior) no sul do Brasil, Publicação Especial, UFRGS, (no prelo).

Parker D.F. 1983. Origin of the Trachyte-quartz trachyte-peralkalic rhyolite suit of the Oligicene Paisano volcano, Trans-pecos Texas. Bull. G.S.A., 94:614-629.

Pearce J.A. 1982. Trace element caracteristics of lavas from destructive plate bourdaries. In: R.S. Thorpe (Ed.) Andesites: orogenic andesites and related rocks. Chichester: Wiley. p. 525 548.

Pearce T.H., Harris N.B.W., Tindle A.G. 1984. Trace element discrimination diagrams for the tectonic interpretation of granitic rocks. Jour. Petrol., 25:956-983.

Remus M.V.D., McNaughton N.J., Hartmann L.A., Fletcher I.R. 1998. U-Pb SHRIMP zircon dating and Nd isotope data of granitoids of the São Gabriel Block, southern Brazil: evidence for an Archean/Paleoproterozoic basement. In: Intern. Simp. Granites and Associated Mineraliations, 2, Extended Abstract Vol., pp.: 271-272.

Reid M.R. 1995. Processes of Mantle Enrichment and Magmatic Differentiation in the Eastern Snake River Plain: Th isotope evidence. Ear. Planet. Sci. Lett., 131:239-254.

Ribeiro M., Bocchi P.R., Figueiredo Filho P.M., Tessari R.I. 1966. 
Geologia e recursos minerais do grau de Caçapava, RS. Rio de Janeiro, DNPM.

Santos E.L., Beckel J., Macedo P.M., Gonzales Filho F., Chaban M. 1978. Divisão lito-estratigráfica do Eo-Cambriano ao PréCambriano superior do Escudo Sul-Riograndense. In: SNG Congr. Bras. Geol., 30, Recife, Anais..., v. 6, pp.: 2562-2575.

Schmincke H.-U. 1974 Volcanological aspects of peralcaline silicic weld ash-flow tuffs. Bull. Volcanol. 38:594-636.

Smith I.E.M, Chappell B.W., Ward G.W., Freeman R.S. 1977. Peralkaline rhyolites associated with andesitic arcs of the Southwest Pacific. EPSL., 37, pp.230-236.

Soesoo A. 1997 Oceanic magmatism and diverse plutonic products within the Thverarindur central volcanic complex at the former Icelandic plate margin. J. Geol. Soc. London, 154:483-489.

Sommer, C.A., Nardi, L.V.S. \& Lima, E.F. 1993 O vulcanismo ácido alcalino no Platô do Taquarembó, Dom Pedrito, RS. In: Simp. Intern. Neoproterozóico-Cámbrico en la cuenca del Plata, 1, Rocha, Uruguay, Extended Abstracts, pp.: 40-45.

Thompson R.N., Dickin A.P., Gibson I.L., Morrison M.A. 1982. Elemental fingerprints of isotopic contamination of Hebridean Palaeocene mantle-derived magmas by Archaean sial. Contr: Mineral. Petrol. 79:159-68.

Walker J.A., Williams S.N., Kalamarides R.I., Fiegerson M.D. 1993. Shallow open-sistem evolution of basaltic magmas beneth a subduction zone volcano: the Masaya Caldera Complex, Nicaragua. J. Volcanol. Geoth. Res., 56:379-400.

Watson E.B. 1979. Zircon saturation in felsic liquids: experimental results and applications to trace element geochemistry. Cont. Mine. Petr:, 70:407-419.
Weaver S.D., Gibson I.L., Houghton B.F., Wilson C.J.N. 1990. Mobility of rare earth and othe elements during crystallization of peralkaline silicic lavas. J. Volcan. Geoth. Res., 43:57-70.

Weaver S.D. 1991. The origin of ocean island basalts end-member compositions: trace elements and isotopic constraints. Ear: Planet. Sci. Lett., 104:381-397.

Wildner W., Sander A., Lopes R.C. 1994. Caracterização petrográfica e litoquímica da Formação Acampamento Velho. Pesquisasis, Porto Alegre, 21:47-57.

Wildner W. \& Lima E.F. 1998. Ciclos vulcânicos nas Bacias do Camaquã e Santa Bárbara representantes do final do magmatismo relacionado a Orogenia Brasiliano/Pan-Africana no sul do Brasil. In: Congr: Latinoam. Geol., 10, Buenos Aires, Anais ...

Wichester J.A. \& Floyd P.A. 1977. Identification and discrimination of altered and metamorphosed volcanic rocks using immobile elements. Chem. Geol., 21:291-306.

Wood D.A., Tarney J., Weaver B.L. 1981. Trace element variations in Atlantic Ocean basalts and Proterozoic dykes from northwest Scotland: their bearing upon the nature and geochemical evolution of the upper mantle. Tectonophysics, 75:91-112.

Wyllie P.J. 1994. Experimental petrology of upper mantle materials, processes and products. In: Intern. Symp. Physics and Chemistry of the Upper Mantle, Invited Lectures, São Paulo, pp.167226.

Manuscrito A-1125

Recebido em 26 de setembro de 1999

Revisão dos autores em 10 de julho de 2002 Revisão aceita em 15 de julho de 2002 